Article

\title{
The Antarctic Centennial Oscillation: A Natural Paleoclimate Cycle in the Southern Hemisphere That Influences Global Temperature
}

\author{
W. Jackson Davis ${ }^{1,2, *}$, Peter J. Taylor ${ }^{1}$ and W. Barton Davis ${ }^{1}$ \\ 1 Environmental Studies Institute, Santa Cruz, CA 95062, USA; ethos_uk@onetel.com (P.J.T.); \\ wbartdavis@yahoo.com (W.B.D.) \\ 2 Division of Physical and Biological Sciences, University of California, Santa Cruz, CA 95064, USA \\ * Correspondence: JacksonDavis@EnvironmentalStudiesInstitute.org or jacksondavis@earthlink.net
}

Received: 5 October 2017; Accepted: 3 January 2018; Published: 8 January 2018

\begin{abstract}
We report a previously-unexplored natural temperature cycle recorded in ice cores from Antarctica-the Antarctic Centennial Oscillation (ACO) - that has oscillated for at least the last 226 millennia. Here we document the properties of the ACO and provide an initial assessment of its role in global climate. We analyzed open-source databases of stable isotopes of oxygen and hydrogen as proxies for paleo-temperatures. We find that centennial-scale spectral peaks from temperature-proxy records at Vostok over the last 10,000 years occur at the same frequencies $( \pm 2.4 \%)$ in three other paleoclimate records from drill sites distributed widely across the East Antarctic Plateau (EAP), and $>98 \%$ of individual ACOs evaluated at Vostok match 1:1 with homologous cycles at the other three EAP drill sites and conversely. Identified ACOs summate with millennial periodicity to form the Antarctic Isotope Maxima (AIMs) known to precede Dansgaard-Oeschger (D-O) oscillations recorded in Greenland ice cores. Homologous ACOs recorded at the four EAP drill sites during the last glacial maximum appeared first at lower elevations nearest the ocean and centuries later on the high EAP, with latencies that exceed dating uncertainty $>30$-fold. ACO homologs at different drill sites became synchronous, however, during the warmer Holocene. Comparative spectral analysis suggests that the millennial-scale AIM cycle declined in period from 1500 to 800 years over the last 70 millennia. Similarly, over the last 226 millennia ACO repetition period (mean 352 years) declined by half while amplitude (mean $0.67^{\circ} \mathrm{C}$ ) approximately doubled. The period and amplitude of ACOs oscillate in phase with glacial cycles and related surface insolation associated with planetary orbital forces. We conclude that the ACO: encompasses at least the EAP; is the proximate source of D-O oscillations in the Northern Hemisphere; therefore affects global temperature; propagates with increased velocity as temperature increases; doubled in intensity over geologic time; is modulated by global temperature variations associated with planetary orbital cycles; and is the probable paleoclimate precursor of the contemporary Antarctic Oscillation (AAO). Properties of the ACO/AAO are capable of explaining the current global warming signal.
\end{abstract}

Keywords: Antarctic Oscillation; Southern Annular Mode; Antarctic Isotope Maxima; Dansgaard-Oeschger oscillations; ice cores; paleoclimate; Holocene; AICC2012; Vostok; anthropogenic global warming

\section{Introduction}

Global temperature has oscillated at least since the beginning of the Phanerozoic Eon 542 million years (My) ago, manifest as long climate cycles that repeat with a period of 135-150 My [1-3]. Faster and smaller temperature oscillations are superimposed on the cooling phase of the most recent long cycle beginning at least $\sim 55$ million years before present (Mybp) [4], forming the earliest Marine Isotope 
Stages (MISs; [5]), or global glacial cycles ("ice ages"). MISs recurred initially every $~ 41$ thousand years (Ky) [5], the same repetition period as the integrated Obliquity/Precessional Orbital Cycle (OPOC; [6,7]), and grew larger by more than an order of magnitude over millions of years as the Earth cooled an additional $\sim 1.5^{\circ} \mathrm{C}$ [5]. MISs shifted to a quasi-regular period of $\sim 80-120 \mathrm{Ky}$ and doubled in amplitude at the Mid-Pleistocene Climate Transition 1.25-0.75 My ago [5,8-14]. This temperature-oscillation pattern continues to dominate multi-millennial climate variability up to the present, inducing quasi-regular global glaciations separated by shorter warm interstadials. The contemporary climate constitutes a prolonged warm interstadial comparable to those that have alternated in the past with cold stadials corresponding to global glacial maxima.

Superimposed upon these multi-millennial climate cycles are numerous shorter global and regional climate cycles ranging in period from several millennia down to a few weeks. Included among these faster oscillations are millennial-scale cycles, particularly the Bond cycle [15-23], and centennial-scale cycles, notably the Antarctic Oscillation (AAO) known also as the Southern Annular Mode (SAM) and tracked quantitatively by means of the Southern Oscillation Index (SOI) [24-31]. These interdependent Southern Hemisphere (SH) temperature-proxy oscillations exhibit both centennial [24-27] and decadal [28-31] frequency components. Similar periodicity appears in independent reconstructions of more contemporary temperature proxies from James Ross Island [27] and snow accumulation in stacked records from snowpits at Vostok [32].

These and other centennial-scale temperature oscillations recurred with regularity in the past and are, therefore, likely to continue to oscillate at similar periods to affect future climate [33]. Understanding these cycles can therefore improve the empirical basis for climate projection across time scales most immediately pertinent to human affairs, decades to centuries [34,35]. Analysis of oscillatory climate regimens and their interactions on diverse time scales also promises to improve our understanding of regional and global climate dynamics, including especially the balance between human and natural forcing of present and future climate change, which are among today's most compelling environmental and policy issues.

Toward these ends we report here a previously-unexplored centennial-scale temperature-proxy oscillation, the Antarctic Centennial Oscillation (ACO), recorded in stable isotopes frozen in ice cores at Vostok, Antarctica [36,37] and three additional Antarctic drill sites distributed widely on the East Antarctic Plateau (EAP), namely, EPICA Dronning Maud Land, EPICA Dome C and Talos Dome. Paleoclimate records from these four drill sites have been synchronized on the most precise ice-core chronology available, the Antarctic Ice Core Chronology of 2012, or AICC2012 [38,39], enabling the most accurate possible estimates of the relative timing of ACO occurrence at different drill sites.

Centennial-scale temperature oscillations in the Vostok paleoclimate record were recognized qualitatively nearly two decades ago [40], but their nature and spatial extent have not been characterized previously, "precluding a definitive conclusion about their meaning" [40] (p. 111). Here we characterize the ACO quantitatively, document its occurrence at the aforementioned four ice-core drill sites on the EAP, explore the ACO contribution to Dansgaard-Oeschger (D-O) oscillations in the Northern Hemisphere (NH), draw parallels with contemporary climate cycles including particularly the Antarctic Oscillation (AAO), and evaluate possible implications for the current and future climate.

In particular, the contemporary global warming increase of $\sim 0.8^{\circ} \mathrm{C}$ recorded since 1850 has been attributed widely to anthropogenic emissions of carbon dioxide $\left(\mathrm{CO}_{2}\right)$ into the atmosphere. Recent research has shown, however, that the concentration of $\mathrm{CO}_{2}$ in the atmosphere has been decoupled from global temperature for the last 425 million years [3] owing to well-established diminishing returns in marginal radiative forcing $(\triangle \mathrm{RF})$ as atmospheric $\mathrm{CO}_{2}$ concentration increases. Marginal forcing of temperature from increasing $\mathrm{CO}_{2}$ emissions declined by half from 1850 to 1980, and by nearly two-thirds from 1850 to 1999 [3]. Changes in atmospheric $\mathrm{CO}_{2}$ therefore affect global temperature weakly at most. The anthropogenic global warming (AGW) hypothesis has been embraced partly because "...there is no convincing alternative explanation ..." [41] (p. 12). The ACO provides 
a possible alternative explanation in the form of a natural climate cycle that arises in Antarctica, propagates northward to influence global temperature, and peaks on a predictable centennial timetable.

\section{Methods}

Open-access databases containing stable isotope records [36-38] and computed planetary orbital (Milankovitch) parameters and consequent surface insolation [6,7] were analyzed using conventional methods detailed in the Supplementary Materials (SM). The cycle nomenclature proposed by Wunsch [42] was modified for the centennial-scale Antarctic cycles identified here. The start time for this analysis, 226,408 years before 1950 (yb1950), is the oldest for which the sampling resolution of the Vostok temperature-proxy record is sufficient to detect centennial-scale events in compliance with the Nyquist-Shannon sampling-frequency criterion of two samples per cycle (SM). Oxygen and hydrogen isotope ratios are used widely and interchangeably as paleoclimate temperature proxies [43-47], although the former contains a proxy component of ice volume and other environmental signals not present in the latter $[43,48]$. We use both proxies in this study as is conventional.

Three definitions were used to describe temperature-proxy oscillations comprising ACOs: oscillations larger than $0.25{ }^{\circ} \mathrm{C}$ in amplitude ( $90 \%$ of 546 cycles identified over 226 millennia), oscillations from 0.045 to $0.25^{\circ} \mathrm{C}$ in amplitude ( $10 \%$ of 546 cycles), and small oscillations characterized by a positive inflection of the temperature-proxy record followed by a negative inflection on a rising or falling background temperature-proxy curve (an additional 104 cycles creating a maximum sample size $n=650$ ). These smallest ACOs are accompanied by larger homologs in climate records from other drill sites, showing that they are genuine temperature-proxy oscillations and not noise. The third definition was used only to compute cycle period; excluding it increased mean computed period by $\sim 15 \%$. All other properties of ACO cycles were computed using only the first and second ACO cycle definitions. ACO properties evaluated include period (trough-to-trough and peak-to-peak), amplitude (half the excursion of the warming phase plus half the excursion of the cooling phase), and warming and cooling duration and rate, as detailed in the SM. Reduction of temperature-proxy and atmospheric carbon dioxide $\left(\mathrm{CO}_{2}\right)$ concentration data to analytic format and color-coding of centennial-scale climate cycles depicting the above three definitions appear in SM Table S1, enabling replication of this study and supporting further independent analysis.

This study is limited to East Antarctic temperature-proxy records from ice cores extracted from four drill stations on the EAP synchronized on the AICC2012 chronology: Vostok, EPICA Dome C (EDC), Talos Dome (TD) and EPICA Dronning Maud Land (EDML) [38]. Meaningful comparison of ACO cycles across these diverse climate records required equalizing corresponding sampling resolutions as closely as possible to Vostok by averaging (filtering). The averaging protocols for non-Vostok records were established using a simple arithmetic protocol (SM) and are required to replicate the results of our study. Averaging protocols are therefore reported in figure legends as the bin width over which averages were computed from the original raw temperature-proxy data followed in parentheses by the start time of the averaging. Quantitative analysis of the timing of homologous cycles in different climate records was restricted to the most recognizable cycles associated with well-established climate events. These unambiguous "signpost" ACO cycles can be matched objectively based on their position relative to known climate events, following the methodology established by numerous previous climate investigators [38,40,49].

We used standard quantitative methodologies in this study, including Fourier (spectral) analysis, auto- and cross-correlation, and conventional $t$-tests. Our results show, however, that climate data including those evaluated here do not necessarily comprise a stationary time series, implying that modern advanced methods that assume neither linearity nor stationarity may be more appropriate. Such methodologies include, to various degrees, Wavelet Analysis (which is nonetheless based on the Fourier transform), Empirical Mode Decomposition, Hilbert-Huang transform, etc. We consider these more advanced analytic approaches unnecessary in this initial analysis of the ACO, but our findings nonetheless imply that their absence here constitutes a methodological limitation. As developed in 
the Discussion, we consider this limitation inconsequential because we mainly evaluated short time segments of the climate record that comprise relatively stationary time series as confirmed by autoand cross-correlation results.

We evaluated the major potential sources of noise in the reconstructed climate records, including frequency aliasing, dating uncertainty, variance in cycle amplitude, cycle periodicity, sample resolution and stratigraphic noise from non-climate signals in the original ice-core records, and concluded that they did not affect the present interpretations significantly (SM). The SAS JMP software used here for spectral power analysis employs Fisher's Kappa Test Statistic ( $k$ ) as a white-noise test (SM). The $\kappa$ statistic returns the probability that the distribution analyzed is generated by Gaussian (random) white noise against the alternative that the distribution is nonrandom (SM) and is reported in the figure legends. To compute confidence intervals of spectral density peaks, Fourier coefficients were estimated using forward stepwise regression (SM). Such stepwise selection can exaggerate the precision of the alpha estimates by as much as an order of magnitude [50], however, and we therefore conservatively set the confidence limit threshold for spectral peaks at an order of magnitude higher $(0.005,99.5 \%)$ than usual $(0.05,95 \%)$.

\section{Results}

\subsection{Cycle Nomenclature}

We used the cycle nomenclature developed by Wunsch [42] as modified here (SM). By this nomenclature, the ACO documented in the present study is designated as the $\mathrm{TO}_{\mathrm{C} 350 \mathrm{~V}}$ cycle (Temperature-proxy $\underline{\text { Oscillation }}_{\text {Centennial-scale }} \underline{350}$ year mean period $\underline{V a r i a b l e}_{\text {) }}$ ) based on its mean repetition period of 352 years over the time period evaluated, 226.4 to $0.149 \mathrm{Kyb1950}$, and based on the observed systematic variation of ACO period and amplitude in the time series as documented below.

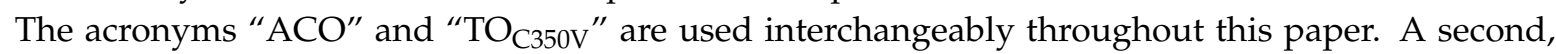
millennial-scale oscillation, termed the $\mathrm{TO}_{\mathrm{K} 1500 \mathrm{~V}}$ cycle using the modified Wunsch nomenclature, appears homologous with the previously-identified Bond cycle in the $\mathrm{NH}$ [17-21] and is also evaluated here using temperature-proxy data from the $\mathrm{SH}$.

\subsection{Cycle Form}

The $\mathrm{TO}_{\mathrm{C} 350 \mathrm{v}}$ cycles analyzed here are evident in raw temperature-proxy records as separate, individually-identifiable oscillations, each composed of several sampling data points (Figure 1). These centennial temperature-proxy cycles are superimposed on ascending temperature phases of MISs such as the Last Glacial Termination (LGT; Figure 1a) and recovery from the Antarctic Cold Reversal (ACR, Figure 1b), on descending phases of the temperature-proxy record such as the cooling phase of the ACR (Figure 1b), and on relatively flat regions of the Vostok temperature-proxy record including the Last Glacial Maximum (LGM) and the Holocene (Figure 1a,d, respectively). All $650 \mathrm{TO}_{\mathrm{C} 350 \mathrm{~V}}$ cycles identified in this study over the $226.4 \mathrm{Ky}$ evaluated using the three definitions described in the Methods are labeled starting with the most recent cycle at 149 yb1950 on the Vostok GT4 glaciological chronology using alphanumeric symbols, following the convention adopted for MISs [5] (Figure 1). These time series show qualitatively an apparent progressive decline in cycle period (an increase in frequency) combined with a proportional increase in cycle amplitude, both of which are confirmed quantitatively below. 


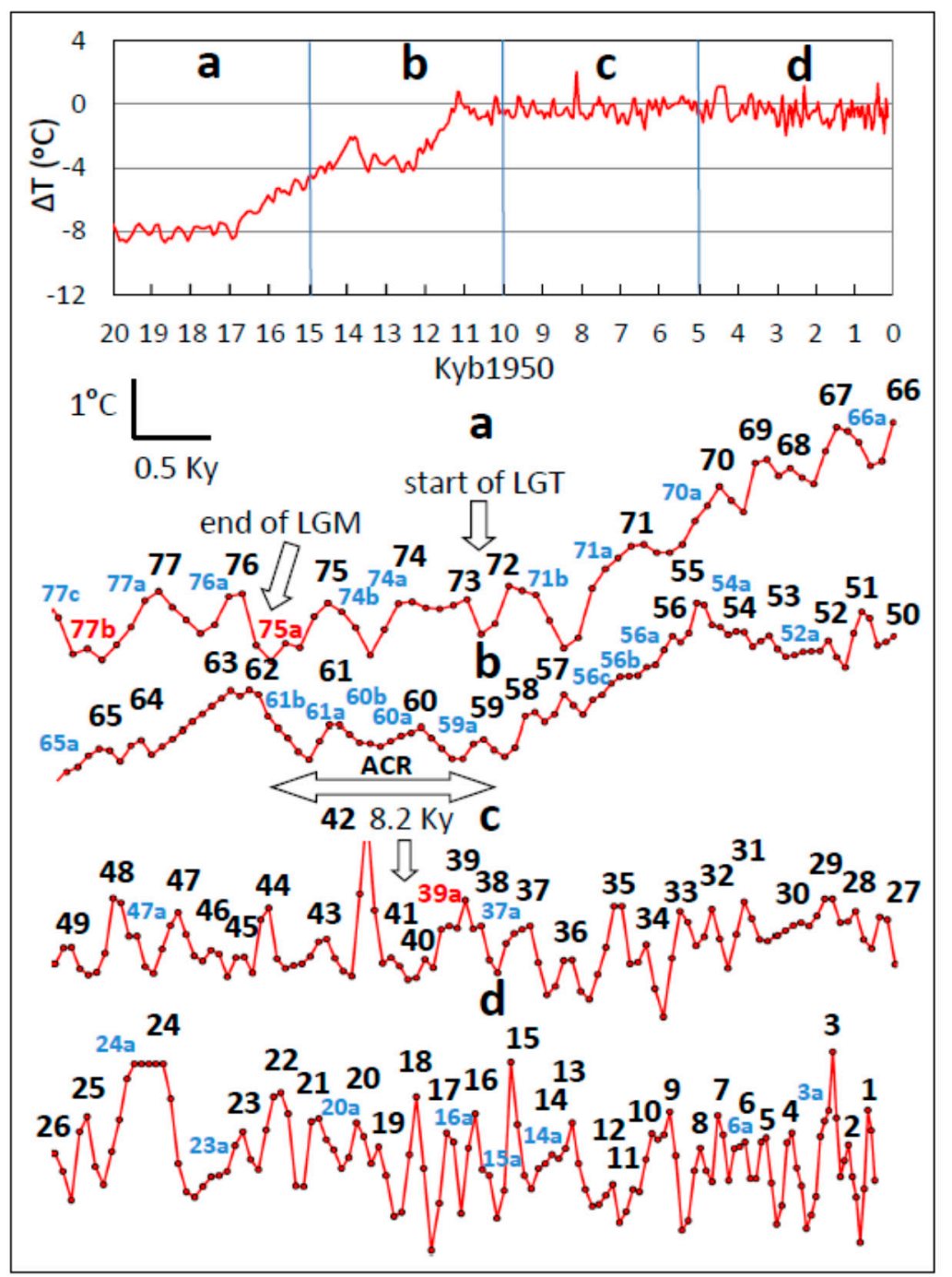

Figure 1. Centennial-scale temperature-proxy oscillations, the Antarctic Centennial Oscillation (ACO), also termed the $\mathrm{TO}_{\mathrm{C} 350 \mathrm{~V}}$ cycle (see text), in the Vostok ice-core record for the last 20 thousand years (Ky). The top panel shows the temperature-proxy record from the Last Glacial Maximum (LGM) to the end of the Holocene divided into quartiles. Time reads from left to right in all records. The lower four panels show the quartiles $(\mathbf{a}-\mathbf{d})$ on an expanded time and temperature scale with every identified $\mathrm{TO}_{\mathrm{C} 350 \mathrm{~V}}$ cycle labeled. Large black numerals correspond to definition 1 (Methods and Supplementary Materials (SM)). Intermediate red and small blue numerals with associated letters correspond to cycle definitions 2 and 3, respectively. Abbreviations here and in subsequent figure captions are: $\Delta \mathrm{T}$, the temperature difference (anomaly) from 1960-1990 of the Current Era (CE) [36,37]; Kyb1950, thousands of years before 1950; ACR, Antarctic Cold Reversal; LGM, Last Glacial Maximum; LGT, Last Glacial Termination. The calibration scale on the left above (a) pertains to all records in (a-d).

\subsection{Cycle Periodicity}

Spectral analysis of Antarctic paleoclimate records was done previously for the Holocene for the time period from 11,500 ybp to the present [51]. We extend this analysis here using the more accurate data synchronized on the AICC2012 chronology and including climate records from Vostok, EDC, EDML and TD; $[38,39]$. We evaluate these climate records over broader time spans than previously done, including the Holocene, and over older and longer time periods, to enable detection of a broader complement of cycle periodicities. The resulting spectral power density periodograms show peaks at decadal, centennial, millennial and multi-millennial periodicities (Figure 2). Spectral peaks occur 
at similar frequencies in ice-core records from different drill sites (cf. Figure 2a,b), consistent with the hypothesis that the same temperature cycles manifest at different Antarctic drill sites located on the EAP.

Broadband periodograms covering several hundred millennia exhibit the primary MIS frequency peak at a period of 106-108 Ky, as well as secondary and tertiary peaks of Milankovitch cycles at the orbital obliquity $(41 \mathrm{Ky})$ and precession $(21 \mathrm{Ky})$ cycle periods (Figure $2 \mathrm{a}, \mathrm{b})$, replicating previous results [36] (cf. our Figure 2a with Figure 4a in [36] (p. 432)). Spectral analysis of shorter records shows possible representations of the obliquity orbital cycles in the Talos Dome climate record at $38.3 \mathrm{Ky}$ (Figure 2c), but corresponding peaks at EDML differ in period by up to $25 \%$ and hence their etiology is correspondingly less certain. The spectral periodograms constructed over shorter time periods (Figure 2c,d) also lack the longer MIS cycle (Figure 2c,d) as expected, since the time period evaluated is too short to detect it.

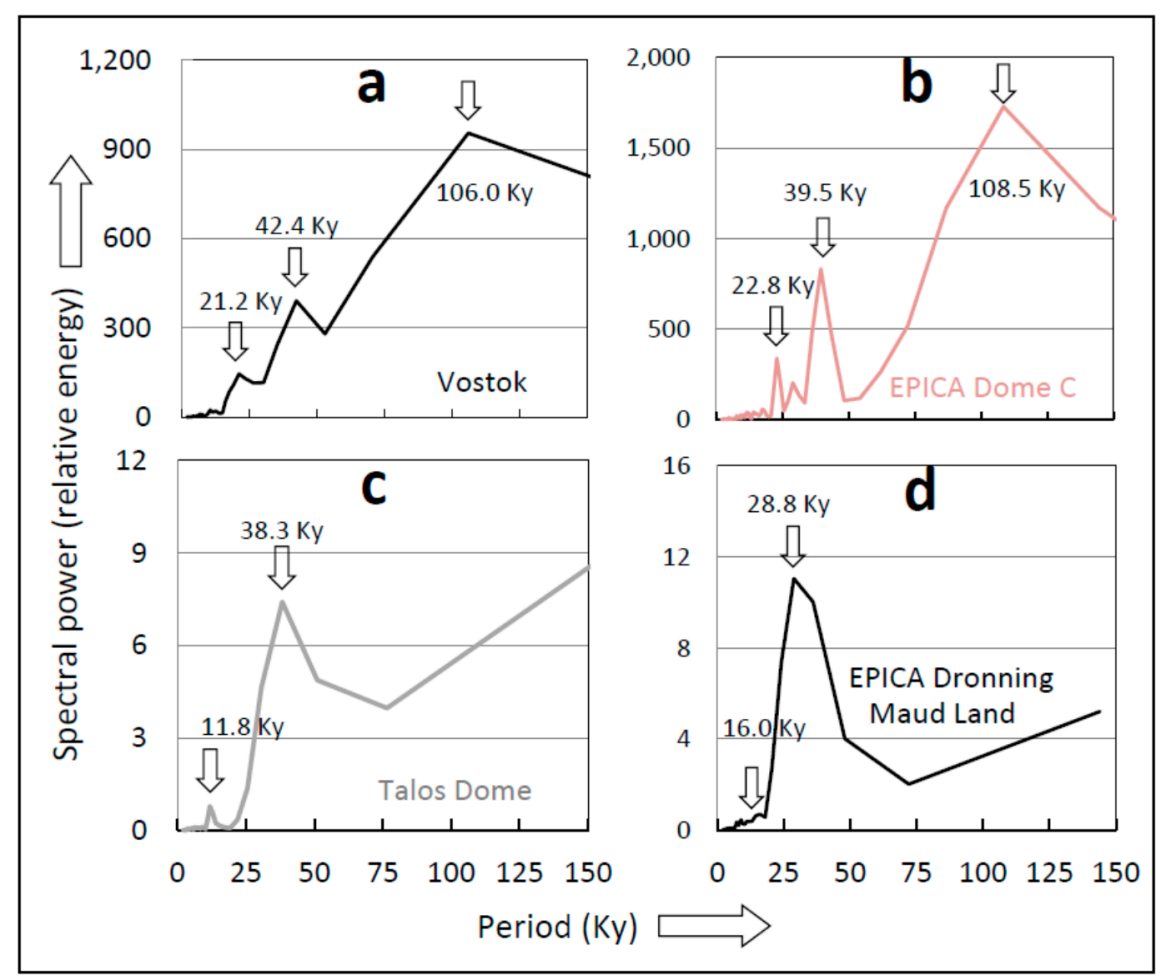

Figure 2. Spectral power density periodograms of temperature-proxy records from four Antarctic drill sites. Arrows and associated numbers designate peaks and corresponding numerical values in thousands of years (Ky). Parts (a,b) span 420 and $434 \mathrm{Ky}$ of the climate record from Vostok and EPICA Dome C (EDC), respectively. The three major peaks in $(\mathbf{a}, \mathbf{b})$ correspond approximately to the Marine Isotope Stages (MIS) cycle (106-108 Ky), the obliquity cycle (41 Ky) and the precession cycle (23 Ky). Parts (c,d) span shorter time periods available for the Talos Dome (TD) (153 Ky) and EPICA Dronning Maud Land (EDML) (144 Ky) climate records, respectively. The absence of a peak near $100 \mathrm{Ky}$ in parts $(\mathbf{c}, \mathbf{d})$ results from the relatively short time period evaluated, which precludes identification of longer multi-millennial cycles (see text). The sites, time periods covered and (in parentheses) Fisher's Kappa (Methods) and the probability that the periodograms result from white noise are: (a) Vostok: 420 to $0 \mathrm{Kyb} 1950$ (44.98, $\left.p<5 \times 10^{-24}\right)$; (b) EDC: 434 to $0 \mathrm{Kyb} 1950\left(59.1, p<3 \times 10^{-28}\right)$; (c) TD: 153 to 0 Kyb1950 (24.73, $\left.p<1 \times 10^{-11}\right)$; (d) EDML: 144 to 0 Kyb1950 $\left(21.36, p<1 \times 10^{-11}\right)$.

Spectral analysis of temperature-proxy records over shorter time periods (narrower frequency

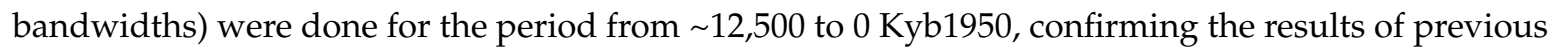
studies [51]. The Vostok periodogram (Figure 3) shows six discernible $(p<0.005)$ centennial-scale spectral power density peaks ranging from 193 years, near the average period of the ACO across 
the Holocene, to 1096 years, near the reported millennial period of the Bond cycle in the NH [17-21]. Relaxation of confidence limits to $95 \%(p<0.05)$ adds three discernible spectral peaks at 282,448 and 580 years which however we do not consider further here owing to the possible exaggeration of precision in the mathematical method used to compute the confidence limits (Methods). These findings confirm previous evidence of multiple centennial peaks over the Holocene [51] (cf. Figure 3 here with their Figure 6, p. 356) and they are reminiscent of multiple discernible spectral peaks recorded in climate records from the NH, e.g., [23].

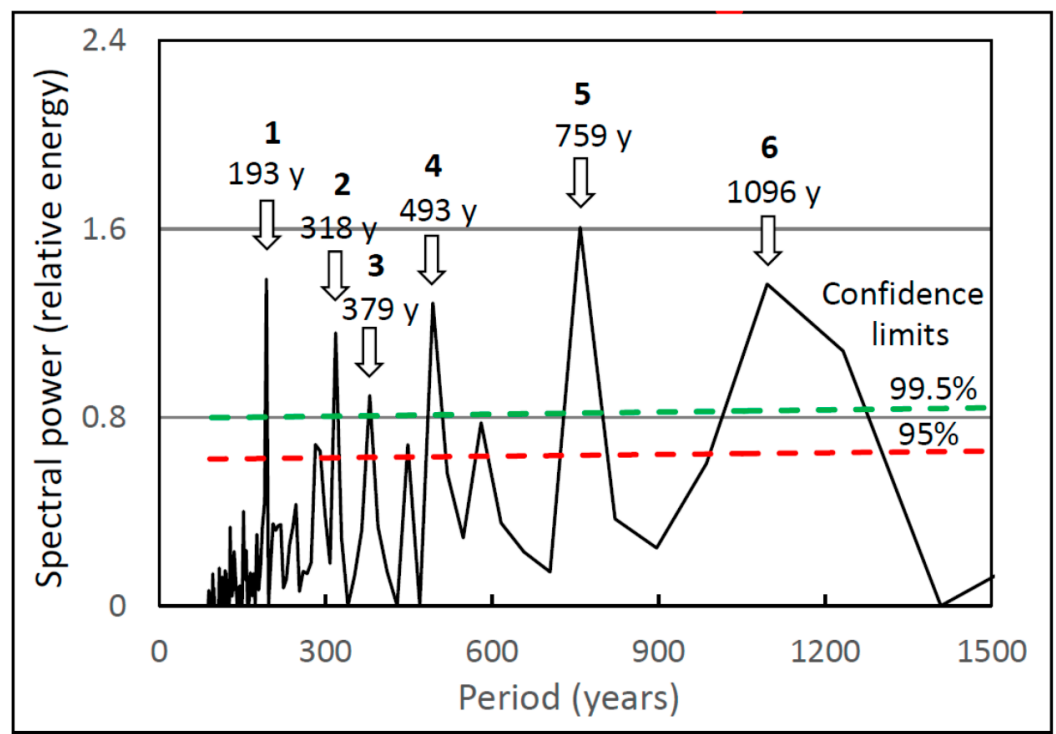

Figure 3. Spectral power density periodogram of temperature-proxy records from Vostok over the Holocene. Arrows and associated numerals designate spectral peaks at the indicated periods in years (y) that are discernible within the indicated confidence limits. Discernible peaks at $p<0.005$ are labeled 1-6 for reference to the same peaks portrayed in subsequent figures. The confidence limits are represented by best-fit exponential curves fitted to stepwise forward regression data over the whole frequency spectrum represented in the periodogram (Methods and SM). Fisher's Kappa and the corresponding probability that the periodogram results from white noise are 17.34 and $p<8.7 \times 10^{-7}$, respectively.

Periodograms of the remaining three AICC2012 climate records during the Holocene are similar to the periodogram of the Vostok record (Figure 4). All are bounded near the low end by a peak corresponding approximately to the mean period of the $\mathrm{TO}_{\mathrm{C} 350 \mathrm{~V}}$ cycles and near the high end by a peak corresponding to the Bond cycle in the $\mathrm{NH}$ and ranging from 825 to 1027 years. Between these extremes lie at least four additional centennial-scale peaks in all AICC2012 climate records evaluated.

The periods of these peaks coincide closely with the six discernible $(p<0.005)$ spectral peaks identified in the Vostok climate record (adjacent arrows in Figure 4 demarcated by ovals). The difference between the closest corresponding peaks in other records was computed in both relative terms (positive and negative signs included) and, more conservatively, in absolute terms (signs omitted). The mean $(n=6)$ relative and absolute differences, respectively, between the frequency of Vostok and non-Vostok spectral peaks (Figure 4 ) are 1.0\% and 5.8\% (Vostok versus EDC; Figure $4 \mathrm{a}$ ), $-1.5 \%$ and $3.8 \%$ (Vostok versus TD; Figure $4 \mathrm{~b}$ ), and $-0.7 \%$ and $4.7 \%$ (Vostok versus EDML; Figure $4 \mathrm{c}$ ). Homologous spectral peaks at different drill sites therefore match each other on average within $\pm 0.2 \%$ (relative difference) or $\pm 2.4 \%$ (absolute difference).

Most but not all matching spectral peaks at EDC, TD and EDML are as distinct as the corresponding peaks in the Vostok record (Figure 4). For example, peak 6 at Vostok with a period of 1096 years, which may be analogous with the Bond cycle in the $\mathrm{NH}$ (the $\mathrm{TO}_{\mathrm{K} 1500 \mathrm{~V}}$ cycle), is matched with a comparable peak at 1050 years in the TD record. We did not assess the statistical discernibility 
of non-Vostok spectral peaks and have no explanation for the occasional apparent differences in relative spectral density energy of peaks that are otherwise matched in period. The findings nonetheless support overall the hypothesis that the same temperature-proxy cycles manifest at geographically-distributed EAP drill sites.

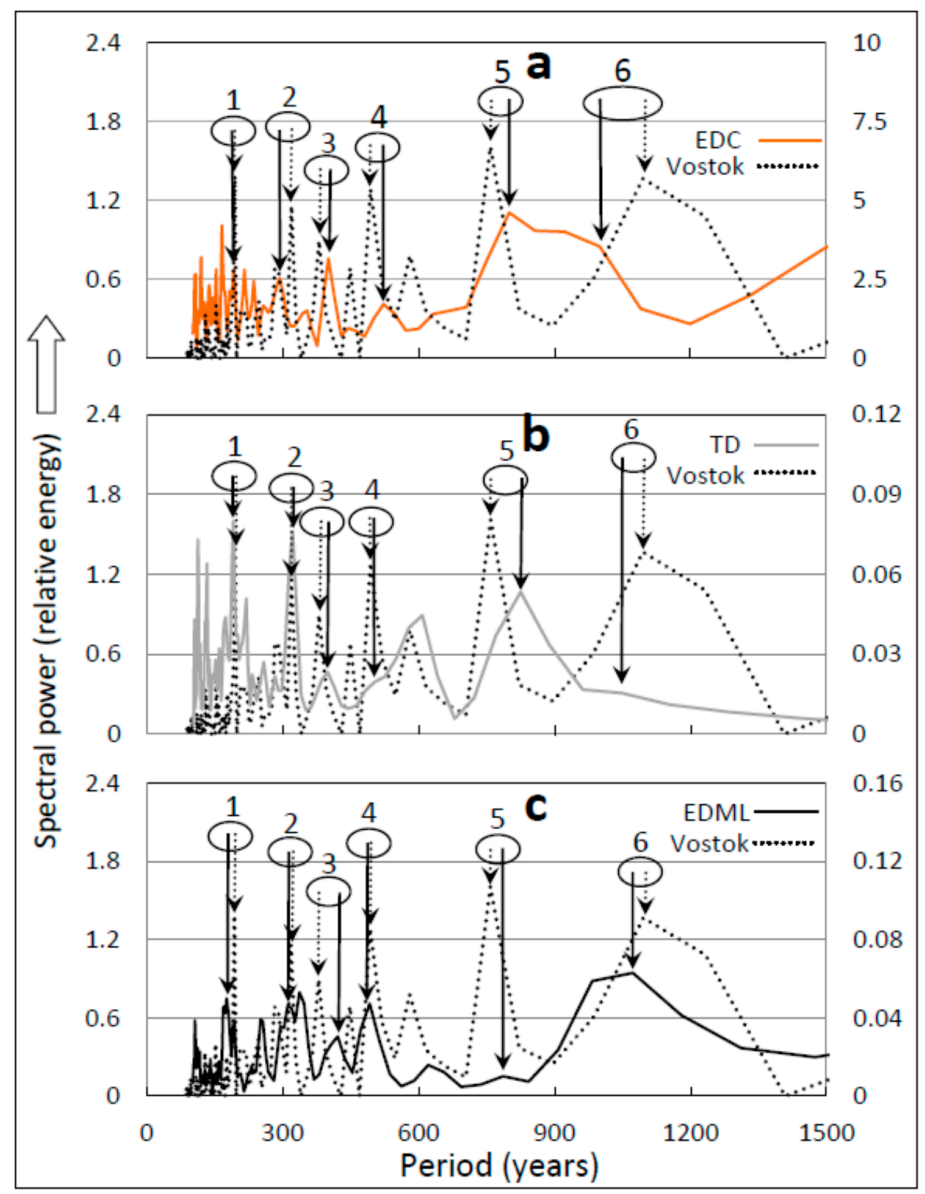

Figure 4. Spectral power density periodograms of Antarctic temperature-proxy records over the Holocene ( 12,000-0 yb1950). Each graph compares the spectral periodogram of Vostok (dotted curves; from Figure 3) with three other drill sites on the East Antarctic Plateau (EAP; solid curves): (a) EDC; (b) TD; and (c) EDML. Ovals encompass arrows designating homologous pairs of spectral peaks, which match on average within $\pm 0.2-2.4 \%$ (see text). This comparison highlights similar spectral peaks in the different climate records, showing the same cycles represented at drill sites dispersed widely on the EAP. Ordinate labels on the left of each graph correspond to Vostok, while ordinate labels on the right correspond to the site compared with Vostok. The sites, time periods covered and (in parentheses) Fisher's Kappa and the corresponding probability that the periodograms result from white noise are: (a) EDC, 12,050 to $\sim 0 \mathrm{Kyb} 1950\left(26.55, p<10^{-11}\right)$; (b) TD, 11,160 to $\sim 0 \mathrm{Kyb} 1950$ $\left(45.1, p<2.76 \times 10^{-23}\right)$; (c) EDML, 12,000 to $\sim 0 \mathrm{Kyb} 1950\left(35.94, p<3.8 \times 10^{-17}\right)$.

Spectral power periodograms of non-stationary time series can be ambiguous in the frequency domain inasmuch as the changing frequency of any variable climate cycle can broaden ("smear") a spectral power peak, rendering it less distinct. Additionally, in the event of discrete frequency shifts in the underlying reference signal, power periodograms can manifest distinct spectral peaks even when they originate from the same, variable (non-stationary) climate cycle. We therefore conservatively sought additional confirmatory evidence for nonrandom periodicity in the time domain of Antarctic climate records in the form of lagged or serial autocorrelation correlelograms. We generated correlelograms over relatively short time frames of the Vostok record dated on the GT4 chronology, 
including from 75 to $55 \mathrm{Kyb1950,} 20$ to ten Kyb1950, and ten to $0.149 \mathrm{Kyb} 1950$. The GT4 chronology for Vostok differs only slightly from the AICC2012 chronology over time periods analyzed here, as demonstrated by the near-identity of the respective age models over the time period studied here (SM Figure S3).

The null hypothesis that $\mathrm{TO}_{\mathrm{C} 350 \mathrm{~V}}$ cycles comprise random variation in cycle structure was tested by means of cyclic autocorrelation coefficients. We find that autocorrelation coefficients alternate between positive and negative at the same periodicity as the corresponding $\mathrm{TO}_{\mathrm{C} 350 \mathrm{~V}}$ cycle frequency (Figure 5). Near peaks and troughs, nearly all of these autocorrelation coefficients are discernibly different from zero at low alpha levels (at least at $p<0.05$ ). These autocorrelation results supplement and extend spectral periodograms to confirm that $\mathrm{TO}_{\mathrm{C} 350 \mathrm{~V}}$ cycles comprise nonrandom periodic sequences. Such positive autocorrelation results would not be possible unless the short time series evaluated represent relatively stationary time series over the time periods evaluated.

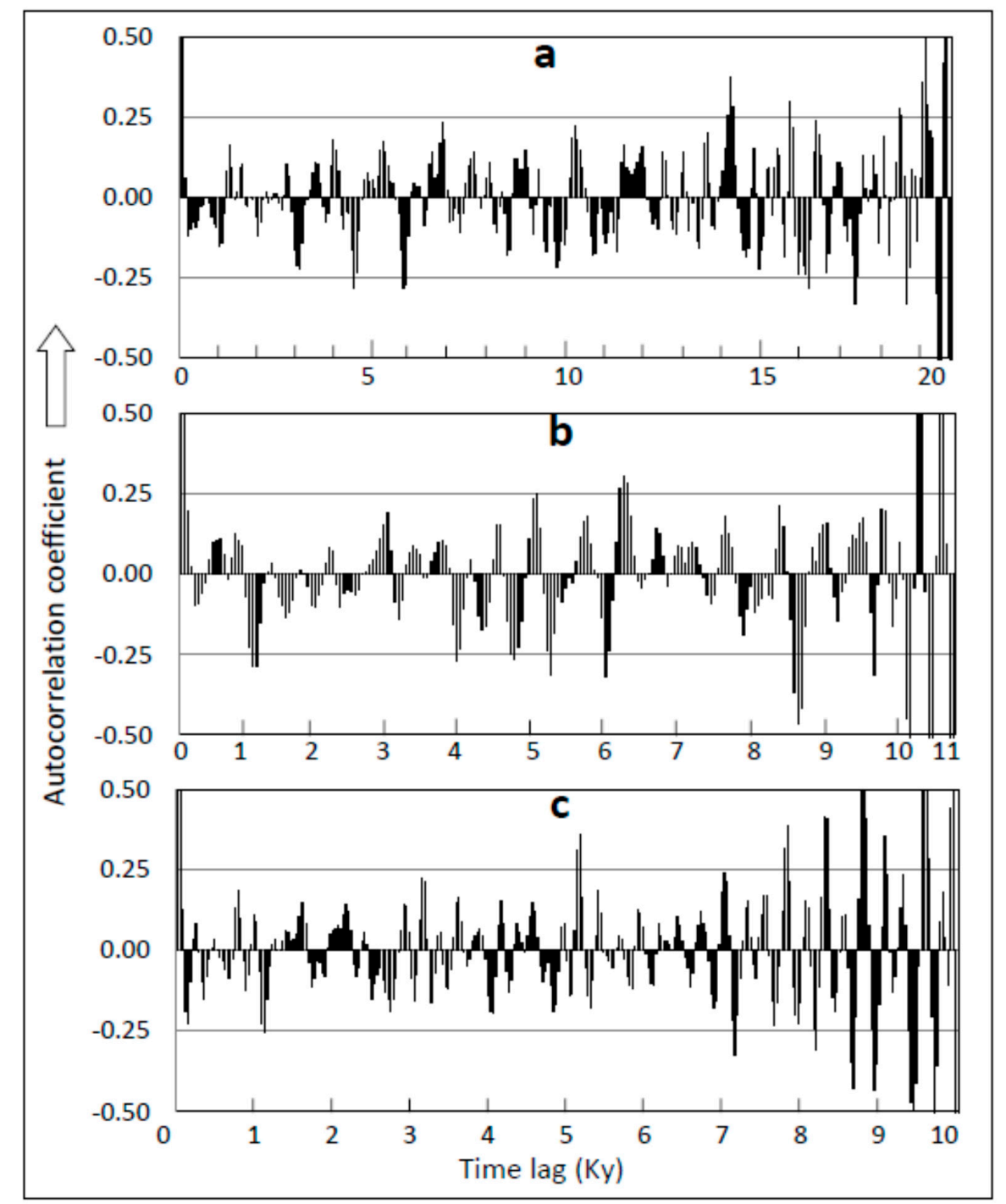

Figure 5. Serial (lagged) autocorrelelograms of the Vostok temperature-proxy record over three representative time periods. These graphs demonstrate nonrandom periodicity in the repetition period of the ACO in the Vostok record and relative stationarity across the designated time periods. The serial autocorrelation coefficient between high-pass filtered and normalized Vostok temperature-proxy records is in each case plotted against the order of the autocorrelation converted to the time lag of the Vostok record shifted stepwise relative to itself (Ky). Time periods represented are: (a) 75 to $55 \mathrm{Kyb} 1950$; (b) 21 to ten Kyb1950; (c) ten to $0.149 \mathrm{Kyb} 1950$. 


\subsection{Geographic Distribution of ACOs}

The demonstration of similar spectral density periodograms at different drill sites on the East Antarctic Plateau suggests that $\mathrm{TO}_{\mathrm{C} 350 \mathrm{~V}}$ cycles are common to all four ice-core records evaluated here. We tested this hypothesis more directly by examining individual $\mathrm{TO}_{\mathrm{C} 350 \mathrm{~V}}$ cycles using the identical approach pioneered by previous investigators, namely evaluation of cycle waveform and sequence (Methods). Three of the four AICC2012-synchronized Antarctic climate records over the period 70 to $63 \mathrm{Kyb} 1950$ were sampled originally at a high enough frequency to detect centennial-scale temperature-proxy oscillations in compliance with the Nyquist-Shannon sampling-frequency criterion: Vostok, the nearby $(\sim 550 \mathrm{~km})$ and slightly lower-elevation $(\sim 248 \mathrm{~m}) \mathrm{EDC}$, and the more distant $(\sim 2300 \mathrm{~km})$ and still lower-elevation ( 596 m) EDML (Figure 6) (distances between drill sites and elevations are from [51]).

The time period from 70 to $63 \mathrm{Kyb} 1950$ encompasses two well-studied climate events, Antarctic Isotope Maximum (AIM) \# 19 and AIM \# 18 [38], which were formerly designated as AIM \# 5 and AIM \# 4 [40], respectively. These AIMs precede D-O events \# 19 and \# 18, respectively, in Greenland ice cores from the NH, with south-to-north propagation latencies of 1.5 to 3.0 millennia [38,40,49,52]. Examination of individual $\mathrm{TO}_{\mathrm{C} 350 \mathrm{~V}}$ cycles shows that AIM \# 19 is composed of multiple $\mathrm{TO}_{\mathrm{C} 350 \mathrm{~V}}$ cycles, identified as ACO 195a, 195 and 194, while AIM \# 18 is composed of TO C350v $_{\text {cycles 186-181. }}$ These identified $\mathrm{TO}_{\mathrm{C} 350 \mathrm{~V}}$ cycles are recognizable across the three climate records compared (grey dashed connector lines in Figure 6), consistent with the hypothesis that $\mathrm{TO}_{\mathrm{C} 350 \mathrm{~V}}$ cycles are distributed geographically across the EAP to at least these three drill sites.

The identified $\mathrm{TO}_{\mathrm{C} 350 \mathrm{~V}}$ cycles that compose AIM \# 19 and AIM \# 18 do not occur at the same time in different climate records, i.e., the homologous cycles at one drill site are shifted forward or backward in time relative to other drill sites when displayed on a common chronology (Figure 6). For example, mean peak-to-peak latencies from Vostok to EDC over ten homologous cycles that encompass AIM \# 19 (cycles 195a-190) was computed as -158.5 years. The negative sign implies that Vostok peaks lag homologous peaks at EDC. Similarly, peaks of the ten $\mathrm{TO}_{\mathrm{C} 350 \mathrm{~V}}$ cycles associated with AIM \# 18, 186a-178 are asynchronous, occurring at a mean time latency from Vostok to EDC of -211.2 years (Vostok lags). In both of these examples, however, the mean latency is smaller than the reported dating uncertainty for this portion of the respective climate records [38] and therefore in these examples the observed difference in latencies cannot be distinguished from chronological noise or dating uncertainty.

In contrast to these examples, the mean latency between the peaks of homologous $\mathrm{TO}_{\mathrm{C} 350 \mathrm{~V}}$ cycles from Vostok to EDML for cycles 195a-190 is -335.1 years (Vostok lags EDML), while the mean latency between homologous cycles $186 a-178$ is -557.7 years (Figure 6a). These means are discernibly greater than the corresponding mean latencies between Vostok and EDC ( $t$-test, $p<0.0006, n=10$ ). The Vostok-to-EDML mean latency also exceeds the sum of the decadal variance that arises from averaging and the estimated dating uncertainty for this glacial period, which is 500 years [38] (p. 1737). These latency differences from Vostok to EDML cannot, therefore, be attributed to dating uncertainty. Instead, the differences in latency between homologous cycles at different drill sites are genuine (non-artifactual) climate signals.

The corresponding mean peak-to-peak latency from EDC to EDML between homologous cycles 195a-190 is -176.6 years (EDC lags), discernibly smaller than the mean latency from Vostok to EDML of -335.1 years $(t$-test, $p<0.0009, n=9)$. For cycles $186 a-178$, the comparable mean homologous peak-to-peak latencies are -322.6 years (EDC to EML) and - 557.6 years (Vostok to EDML), discernibly different from each other $(t$-test, $p<0.0006, n=10)$. Chronological uncertainty reported for this period of the AICC2012 chronology is from 20 to 100 years [38] (p. 1737). The measured differences in mean latencies are therefore not only discernible with high probability but again exceed the dating uncertainty of the AICC2012 chronology, in these examples by a factor up to $>30$. Comparing Vostok-to-EDC latency with EDC-to-EDML latency yields non-discernible differences for cycles 195a-190 ( $p>0.66)$ and cycles 186a-178 $(p>0.13)$. In both cases the corresponding mean latencies nonetheless exceed reported chronological uncertainty. 


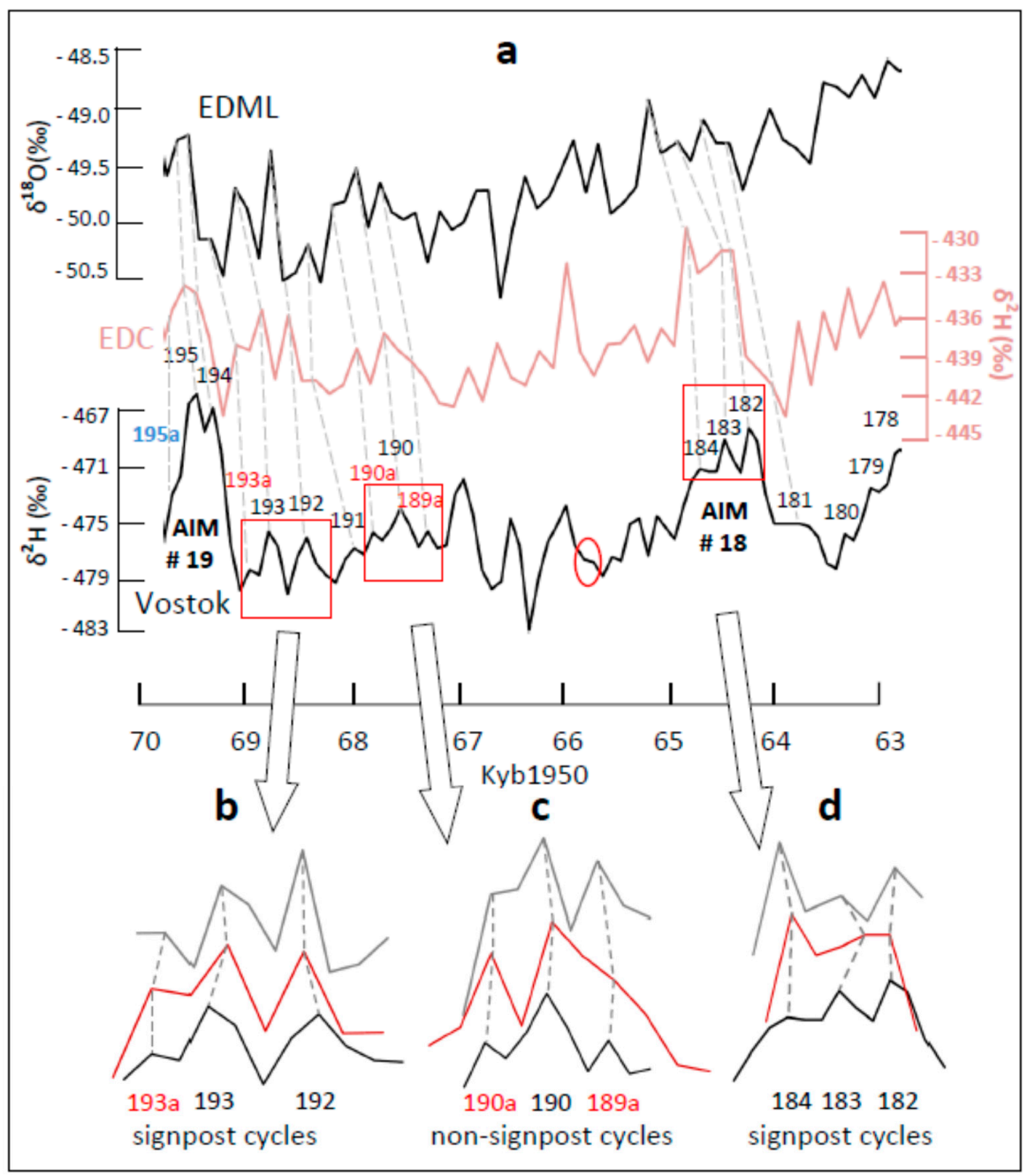

Figure 6. Time series comparing $\mathrm{TO}_{\mathrm{C} 350 \mathrm{~V}}$ cycles at Vostok, EPICA Dome $\mathrm{C}$ (EDC) and EPICA Dronning Maud Land (EDML) over the time period from 70 to $63 \mathrm{Kyb1950.} \mathrm{Labeled} \mathrm{signpost} \mathrm{cycles} \mathrm{in} \mathrm{the} \mathrm{Vostok}$ record (depicted on the GT4 glaciological chronology) are identified in part by their association with other well-known climate events, in this case Antarctic Isotope Maxima (AIMs), which are numbered following corresponding Dansgaard-Oeschger (D-O) events in the Northern Hemisphere (NH) [38]. (a) overview of the respective climate records during this time period. Dashed gray lines connect identified cycles in the different climate records. Parts (b-d) show details of three sections of the record enclosed in red rectangles in (a) in which cycles have been aligned as closely as possible by shifting them in time by the mean differences between peak times (mean latencies). The red oval in this figure (cycle 186b in the Vostok record) and in subsequent figures designates a mismatch, i.e., a cycle that was not matched in the other climate records. Averaging bin widths and start times of averaging (in parentheses, yb1950), which are required to replicate these results from the original AICC2012 sample data (Methods) are: EDC, 2 (60,017.8); EDML, 3 (62,813.1). The Vostok data comprise the original, unfiltered temperature-proxy record [36,37].

The century-scale and discernible differences in peak time latencies across different climate records therefore signify that within the limits of chronological uncertainty, homologous $\mathrm{TO}_{\mathrm{C} 350 \mathrm{~V}}$ climate cycles arrive at different times at the four drill sites analyzed. Homologous cycles appear first at the lowest drill site nearest the ocean (EDML) and centuries later on the high EAP at Vostok and EDC. The latency between sites exceeds the duration of individual cycles and yet the characteristics and sequences of $\mathrm{TO}_{\mathrm{C} 350 \mathrm{~V}}$ cycles are retained across climate records as they propagate from drill stations close to the ocean to more distant sites high on the EAP. Although the expansion and contraction 
of the probably-homologous Antarctic Oscillation (AAO; see below) comprises a standing wave, its cyclic variation imparts apparent movement that is reflected here as changes in latencies between homologous ACO cycles at different drill sites. Retention of the internal architecture of ACO cycles and their sequences as the cycles propagate over time and space reflects a "memory" in the Antarctic climate system at least a few centuries in duration. The differences in latencies of $\mathrm{TO}_{\mathrm{C} 350 \mathrm{~V}}$ cycles identified here parallel and corroborate the timing differences reported between major climate events in Antarctica identified from methane-synchronized Antarctic climate records [53,54].

To enable a more direct visual comparison of relative waveforms, amplitudes and timing of homologous ACOs, the corresponding temperature-proxy records were shifted in time by the mean latency between peaks so that they appear in artificial temporal register (Figure $6 \mathrm{~b}-\mathrm{d}$ ). Waveforms and relative amplitudes of homologous $\mathrm{TO}_{\mathrm{C} 350 \mathrm{~V}}$ cycles appear qualitatively most similar between Vostok and nearby EDC, although comparisons across drill sites separated by greater distances and elevations also often show similar waveforms and relative amplitudes. Smaller-amplitude cycles in one climate record invariably manifest as larger-amplitude cycles in one or more other records, e.g., cycles 193a and 184 at Vostok and cycles 189a and 183 at EDC (Figure 6c,d, respectively). This finding, repeated across all time frames evaluated in this study (not shown), establishes the requirement to include the smallest temperature oscillations under cycle definition 3 (Methods). Waveform matching is 1:1 not only for homologous signpost cycles (Figure $6 \mathrm{a}, \mathrm{c}$ ) but also for homologous non-signpost cycles (Figure 6b).

Spectral analysis of the time period from 70 to $63 \mathrm{Kyb} 1950$ across a narrower (centennial) bandwidth reveals the same spectral density structure seen above in similar records over comparable time periods of the Holocene. That is, the periodogram is bounded near the high-frequency (short-period) end of the spectrum by a centennial-scale peak of approximately the same period as mean $\mathrm{TO}_{\mathrm{C} 350 \mathrm{~V}}$ cycles and on the low-frequency (long-period) end by a long-period cycle of 1471 years (Figure 7). Both of these periods are larger than the corresponding values in more recent time periods, however (cf. Figure 7 with Figures 3 and 4), suggesting that the period of the millennial cycles identified here declines over time, as confirmed more directly below from individual ACO cycles in the time domain. The spectral peak at $1471 \mathrm{y}$ shows nearly the same periodicity as the reported 1470 -year period of Bond events in the NH ([17-21], but see [22,23]). This cycle is designated here as the $\mathrm{TO}_{\mathrm{K} 1500 \mathrm{~V}}$ cycle using the climate-cycle nomenclature modified here from Wunsch [42].

Decomposition of the millennial-scale cycle from the original temperature-proxy time series data (Figure 6a) reveals a characteristic temporal pattern in the sequence of $\mathrm{TO}_{\mathrm{C} 350 \mathrm{~V}}$ cycles that underlies a stereotypic architecture of the $\mathrm{TO}_{\mathrm{K} 1500 \mathrm{~V}}$ cycle. This pattern consists of a largely-monotonic increase over several centuries in the amplitude and frequency of successive $\mathrm{TO}_{\mathrm{C} 350 \mathrm{~V}}$ cycles culminating at the end of each such sequence in a single extreme warming peak followed by a single extreme cooling trough. This stereotypical pattern of $\mathrm{TO}_{\mathrm{C} 350 \mathrm{v}}$ cycle trains is evident in the internal temperature-proxy structure of AIM \# 19 and AIM \# 18 (Figure 6a) and throughout the 226.4 Ky period studied here (not shown) including the Holocene (see below). These observations suggest that AIMs are formed by the periodic (millennial-scale) algebraic summation of sequences of high-frequency $\mathrm{TO}_{\mathrm{C} 350 \mathrm{v}}$ cycles of which they are composed.

The hypothesis that $\mathrm{TO}_{\mathrm{C} 350 \mathrm{~V}}$ and $\mathrm{TO}_{\mathrm{K} 1500 \mathrm{~V}}$ cycles at Vostok comprise more widely-dispersed Antarctic climate signals was evaluated more directly by tracking single, identifiable signpost centennial cycles across the four AICC2012-synchronized climate records over the last 21 millennia (Figure 8). During the LGM and the start of the LGT (Figure 8a), $\mathrm{TO}_{\mathrm{C} 350 \mathrm{~V}}$ signpost cycles include those that occur at the beginning of termination from 18,677 yb1950 (TD) to 18,364 yb1950 (EDC), namely, cycles 74-69. These signpost cycles appear near the time of the onset of the LGT at 18,934 yb1950, as estimated independently from observed sea level minima $(19,000 \mathrm{ybp} \pm 250)$ [55], and are matched one-to-one across all four AICC2012-synchronized climate records (gray dashed connector lines in Figure 8a). Additional $\mathrm{TO}_{\mathrm{C} 350 \mathrm{~V}}$ signpost cycles associated with the ACR from 14,872 (TD) to 
14,456 (Vostok) yb1950, including cycles \# 64-62 at the onset of the ACR (Figure 8a), are among the most recognizable $\mathrm{TO}_{\mathrm{C} 350 \mathrm{~V}}$ signpost cycles identified in this study.

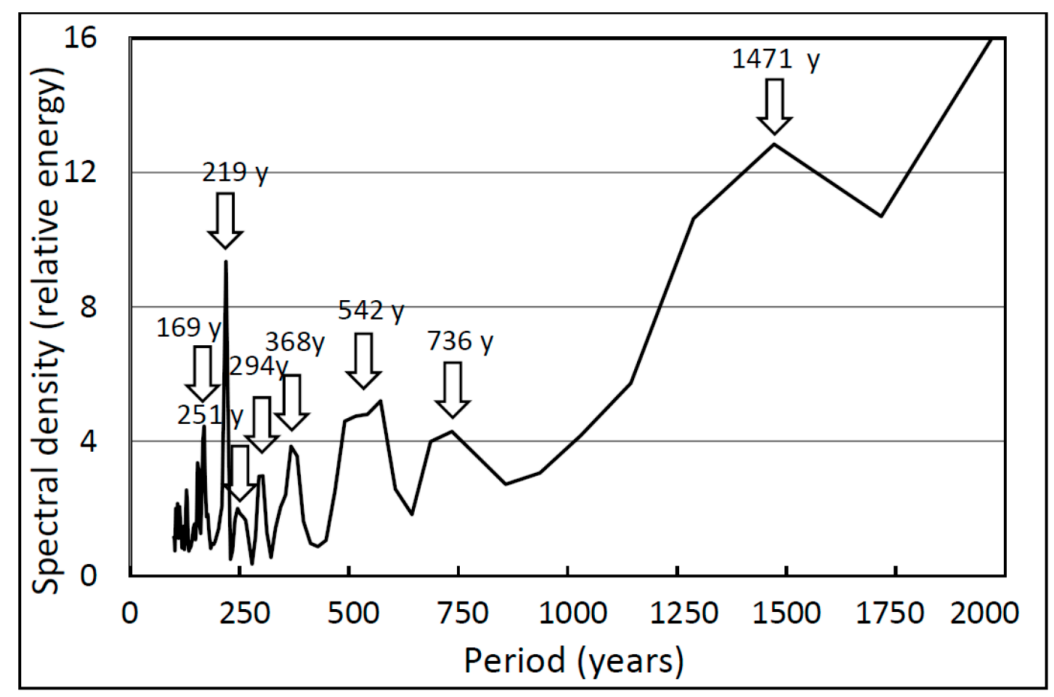

Figure 7. Spectral power density periodogram of temperature records from EPICA Dome C (EDC) for the time period 70 to $63 \mathrm{Kyb1950.} \mathrm{The} \mathrm{arrows} \mathrm{and} \mathrm{associated} \mathrm{numerals} \mathrm{show} \mathrm{peaks} \mathrm{in} \mathrm{the} \mathrm{spectral}$ density of temperature-proxy oscillations and their numerical values in Ky. High-frequency cycles (low period) on the left of the periodogram are interpreted as different higher-frequency components of the ACO, while the low-frequency cycle on the right at 1471 years is interpreted as the $\mathrm{TO}_{\mathrm{K} 1500 \mathrm{~V}}$ cycle similar to the Bond cycle in the NH. Fisher's Kappa and the probability that the periodogram results from white (Gaussian) noise are 51.21 and $p<2.6 \times 10^{-29}$, respectively.

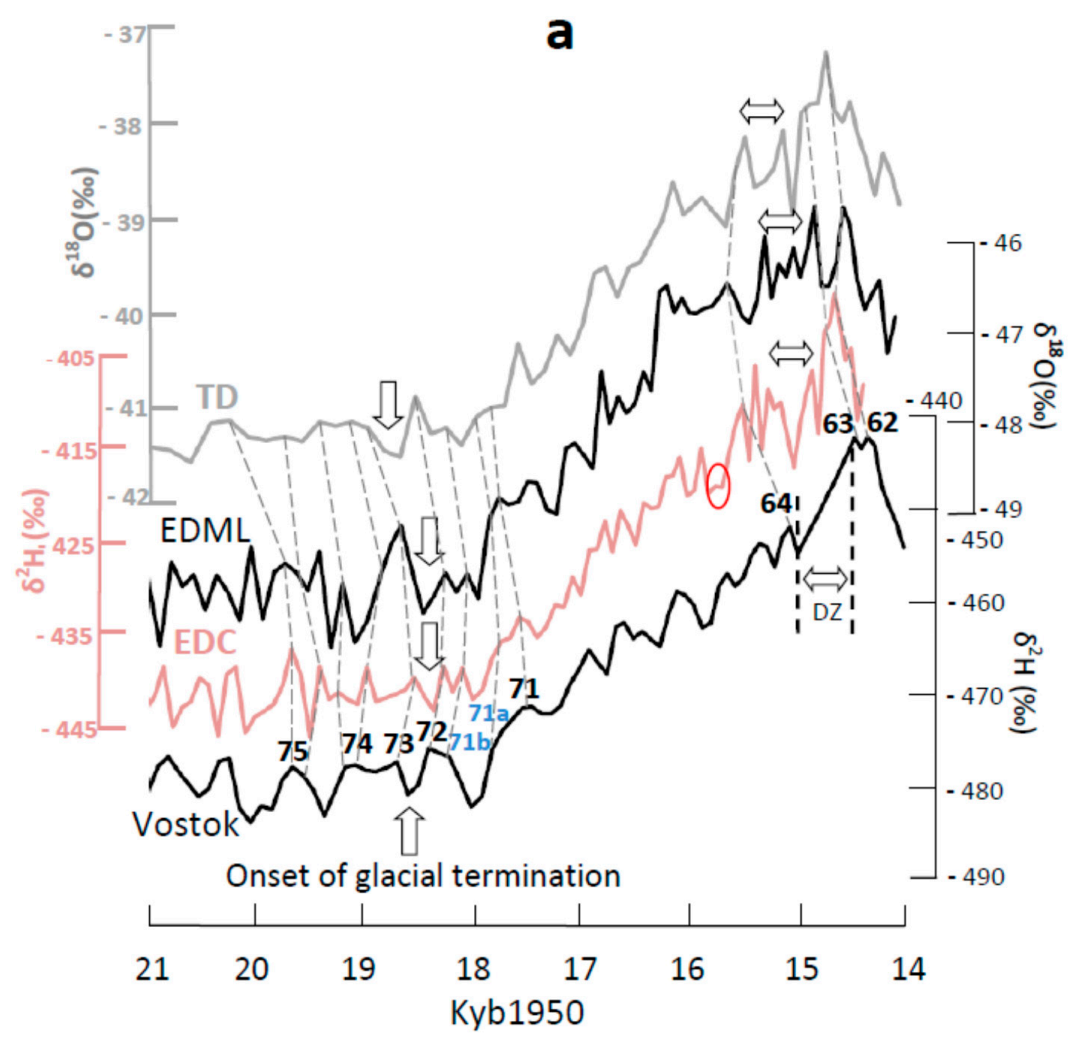

Figure 8. Cont. 

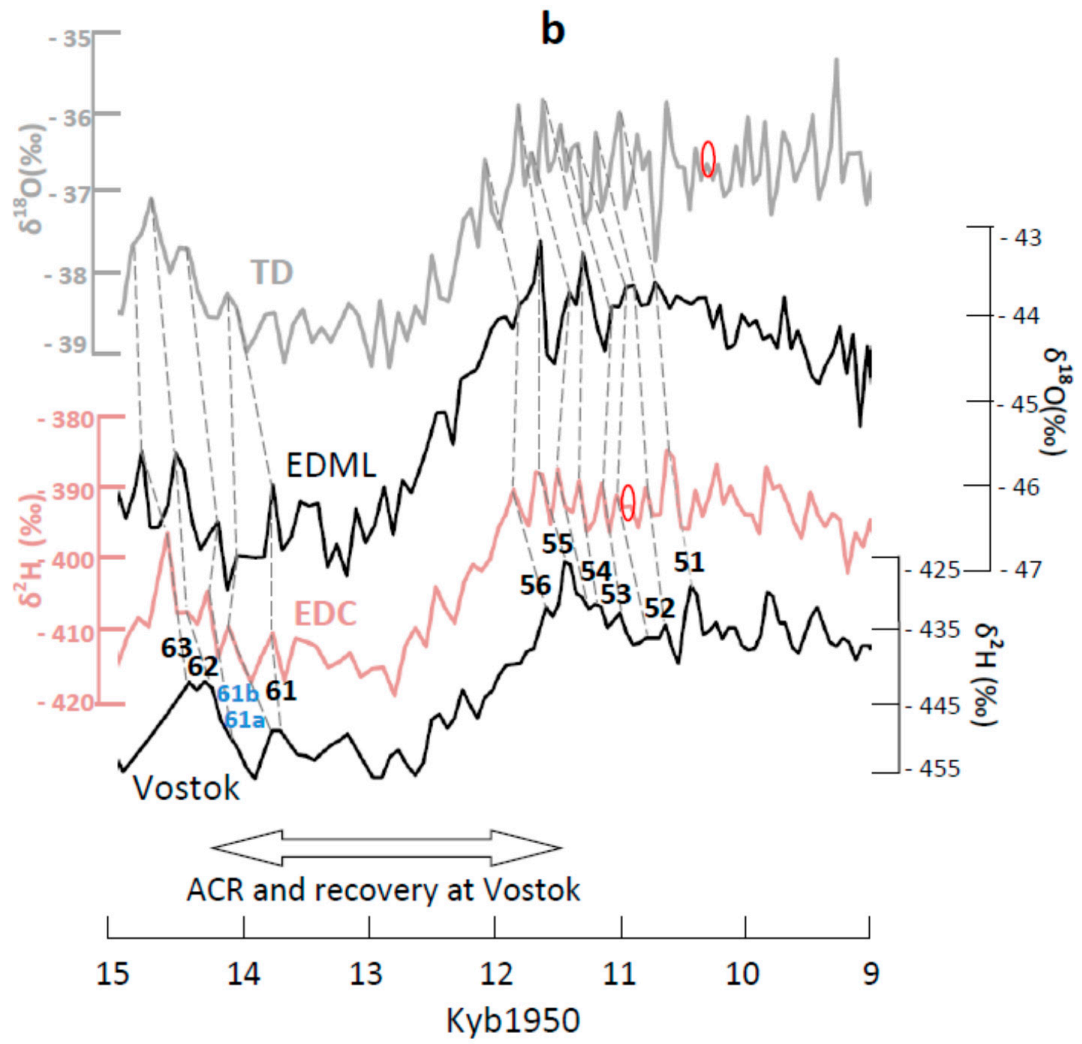

c
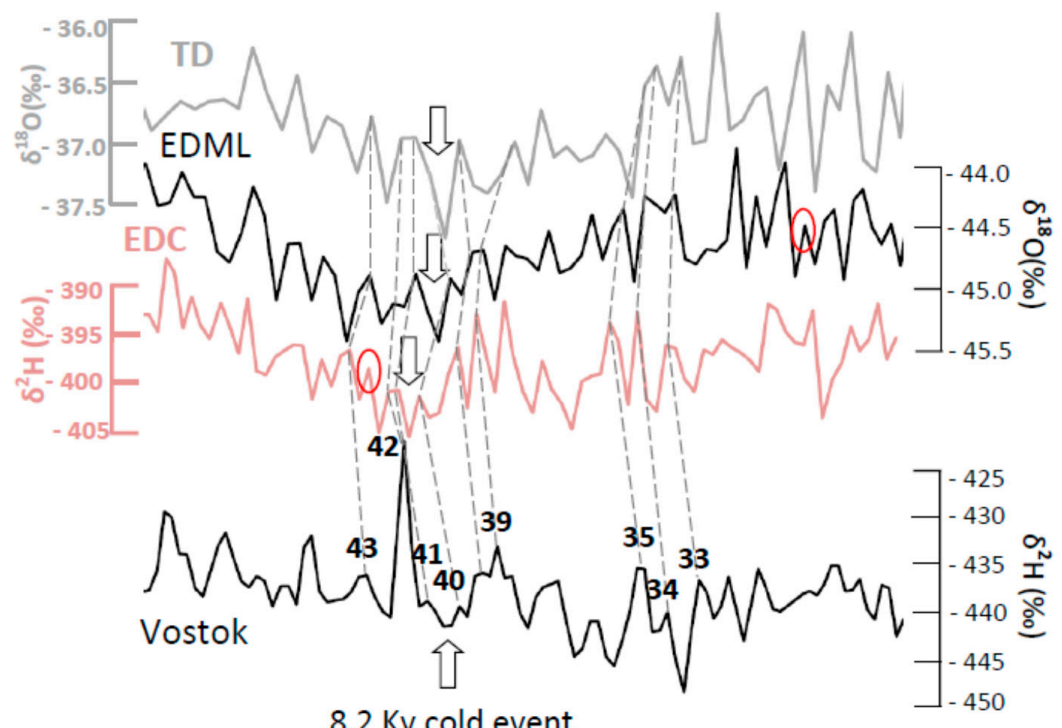

$8.2 \mathrm{Ky}$ cold event

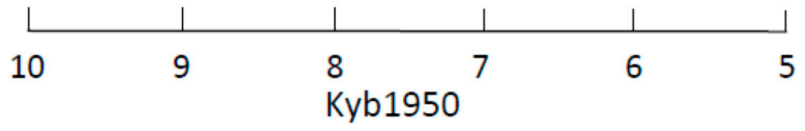

Figure 8. Cont. 


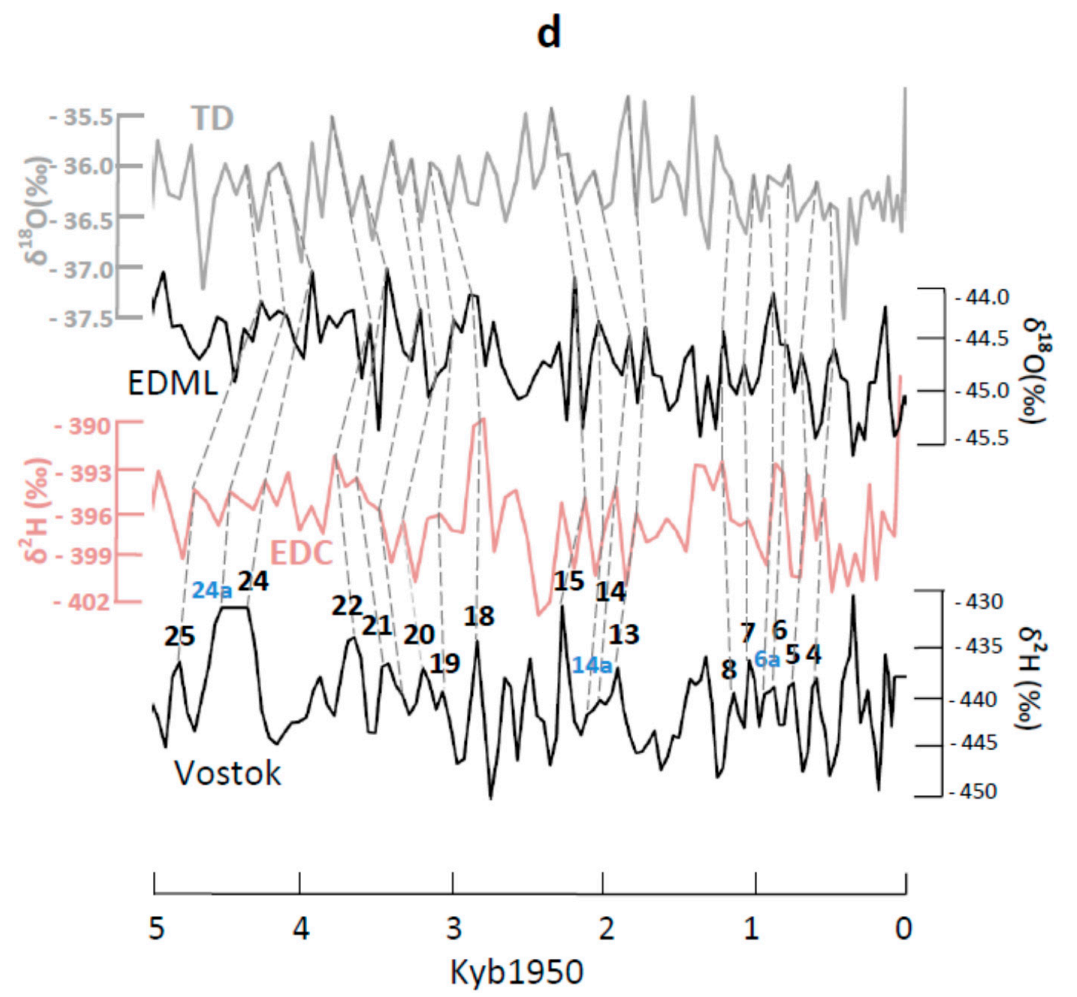

Figure 8. Time series matching identifiable signpost $\mathrm{TO}_{\mathrm{C} 350 \mathrm{~V}}$ cycles across four East Antarctic climate records for the time period 21-0 Kyb1950. These panels illustrate high coherency (1:1 matching) and latency differences of homologous ACOs across the four paleoclimate records analyzed. The Vostok record is presented on the GT4 chronology, while the remaining three records are synchronized on the AICC2012 chronology. Identifiable signpost cycles are labeled at the bottom of each panel on the Vostok record in this and subsequent figures using the color code described in the Methods. Red ovals enclose unmatched ACOs (<2\% of all ACOs). (a) 21 to 14 Kyb1950 showing termination of the Last Glacial Maximum (LGM) at approximately 18,934 yb1950 \pm 250 years (vertical arrow) [55]; (b) 15 to nine Kyb1950 showing glacial termination and the Antarctic Cold Reversal (ACR) at approximately 14.5 to $12.5 \mathrm{Kyb} 1950$ (double-headed arrow); (c) ten to five Kyb1950, the early Holocene. Vertical arrows denote the $8.2 \mathrm{Ky}$ cold event in each record; (d) five to $0.149 \mathrm{Kyb} 1950$, the late Holocene, where signpost cycles are identified by association with the most recent $\mathrm{TO}_{\mathrm{K} 1500 \mathrm{~V}}$ cycles. Abbreviations in all graphs: DZ (a) "dead zone" in which temperature-proxy measurements are apparently missing from the Vostok record. TD, Talos Dome; EDML, EPICA Dronning Maud Land; EDC, EPICA Dome C. Averaging bin widths and start times (in parentheses, yb1950) required to replicate these results are: (a) TD, 2 (14,019.3); EDML, 5 (14,045.6); EDC, 2 (14,362.2). (b) TD, 2 (8839.7); EDML, 5 (8966.4); EDC, 3 (8876.3). (c) TD, 4 (4549.0); EDML, 7 (4525.9); EDC, 3 (5033.8). (d) TD, 4 (-23.8); EDML, 7 (-88.31); EDC, 4 (31.1).

Peak-to-peak latencies between homologous cycles at different drill sites from 21 to $14 \mathrm{Kyb} 1950$ (Figure 8a) follow a different pattern from those described above for the older time period of 70 to $63 \mathrm{Kyb} 1950$ (Figures 6a and 8a). Prior to the LGT (Figure 8a), latencies from $\mathrm{TO}_{\mathrm{C} 350 \mathrm{~V}}$ cycle peaks at Vostok to homologous peaks at EDC are near zero or weakly positive. Latencies from Vostok ACOs to homologs at EDML and especially TD are strongly negative, i.e., Vostok lags. After the LGT begins, however, latencies from Vostok to EDC remain near zero or weakly negative while latencies from Vostok to EDML and especially from Vostok to TD shift toward positive (Figure 8a), i.e., Vostok tends to lead. These latency shifts manifest within a few centuries following the onset of glacial termination. The latency shifts are not ascribable to dating uncertainties across these records, which they exceed by up to more than an order of magnitude as noted above. $\mathrm{TO}_{\mathrm{C} 350 \mathrm{v}}$ cycle latencies between different drill sites are therefore variable and reversible on relatively short geologic time scales. These results suggest 
that glacial termination and the associated increase in temperature transiently synchronized $\mathrm{TO}_{\mathrm{C} 350 \mathrm{~V}}$ peaks across the four AICC2012-synchronized climate records. Cycle coherency, i.e., the percent of identified centennial cycles that are matched 1:1 with homologs in this time frame across all cycles, exceeds $99 \%$. Systematic changes in the latencies between homologous cycles at different drill sites are significant in part because they may bear upon the method of teleconnection between the different drill sites (see below).

Similar analysis of the time period from 15 to 9 Kyb1950 (Figure 8b) shows that signpost TO$_{\text {C350V }}$ cycles are matched 1:1 across all four climate records. The most recognizable signpost $\mathrm{TO}_{\mathrm{C} 350 \mathrm{~V}}$ cycles in this time period occur at the beginning and end of the ACR, namely $\mathrm{TO}_{\mathrm{C} 350 \mathrm{~V}}$ cycles \# 63-61a and cycles \# 56-51, respectively. $\mathrm{TO}_{\mathrm{C} 350 \mathrm{~V}}$ cycle \# 55 demarcates the end of the LGT and the start of the Holocene across all four climate records evaluated and is the single most recognizable $\mathrm{TO}_{\mathrm{C} 350 \mathrm{~V}}$ signpost cycle identified in this study. All remaining non-signpost $\mathrm{TO}_{\mathrm{C} 350 \mathrm{~V}}$ cycles in the Vostok record can also be matched with putative homologs in the other records. Cycle coherency across all cycles in all records is $98.3 \%$, i.e., most centennial-scale cycles in the Vostok record, including both signpost and non-signpost cycles, are matched 1:1 with homologous cycles in the three AICC2012 records, and conversely.

The relative timing of $\mathrm{TO}_{\mathrm{C} 350 \mathrm{~V}}$ cycle peaks over this time period (Figure $8 \mathrm{~b}$ ) shows that Vostok typically lags the other three drill sites and that peak-to-peak latencies generally exceed dating uncertainty. For example, $\mathrm{TO}_{\mathrm{C} 350 \mathrm{~V}}$ signpost cycle \# 62 at Vostok lags its homolog at EDC by 139 years, EDML by 230 years, and TD by 427 years. All three latencies exceed the ten-to-200-year dating uncertainty reported for this time frame [38] (p. 1737) and are larger by up to two orders of magnitude than the decadal variance associated with averaging. Therefore $\mathrm{TO}_{\mathrm{C} 350 \mathrm{~V}}$ cycles \# 62 and \# 55 occur earlier at TD and EDML than the homologous $\mathrm{TO}_{\mathrm{C} 350 \mathrm{~V}}$ cycles at Vostok and this time difference is genuine rather than artifactual.

The time lag between homologous $\mathrm{TO}_{\mathrm{C} 350 \mathrm{v}}$ cycle peaks from TD to Vostok is equivalent to at least two $\mathrm{TO}_{\mathrm{C} 350 \mathrm{v}}$ cycles, implying retention in the climate system of information about the relative amplitude, waveform and sequence of $\mathrm{TO}_{\mathrm{C} 350 \mathrm{~V}}$ cycle \# 62 as this climate signal propagates from TD to Vostok over hundreds of years and thousands of kilometers. These latency differences between the four AICC2012 sites, particularly TD and Vostok, persist throughout this six-Ky period and increase to 750 years, equivalent to from three to four complete $\mathrm{TO}_{\mathrm{C} 350 \mathrm{~V}}$ cycles at the cycle frequency that prevails over this time period. This latency exceeds the corresponding 200-year dating uncertainty and exceeds the uncertainty estimated for comparisons between TD and Vostok of 20-100 years [38] (p. 1737) by a factor of up to 37.5. These findings therefore further exemplify the aforementioned "climate memory", which is expressed as the conservation of $\mathrm{TO}_{\mathrm{C} 350 \mathrm{~V}}$ sequences and cycle parameters across multiple $\mathrm{TO}_{\mathrm{C} 350 \mathrm{~V}}$ cycles and across distances of thousands of kilometers.

The time period from ten to five Kyb1950 (Figure 8c) encompassing the early Holocene shows a different pattern from the earlier time periods analyzed. During the early Holocene, the latencies between homologous $\mathrm{TO}_{\mathrm{C} 350 \mathrm{~V}}$ peaks approach zero across the four AICC2012 climate records. The peak-to-peak latency from TD to Vostok reverses for several cycles starting at approximately eight Kybp, when $\mathrm{TO}_{\mathrm{C} 350 \mathrm{v}}$ peaks at $\mathrm{TD}$ follow corresponding peaks at Vostok. This reversal entails changes in peak-to-peak latencies of up to a few hundred years, which exceed by more than an order of magnitude the summed variance of dating uncertainty (ten to 100 years) and averaging noise (decadal). During this period, the Holocene Climate Optimum, temperature is greater than at any other time analyzed in this study and peak latencies across sites shifts from negative to positive (Vostok leads). These results illustrate that the latencies at different drill sites shift from synchrony to reversal during the warmest climate studied here, the early Holocene. Cycle coherency over the time frame from ten to five Kyb1950 including both signpost and non-signpost cycles is $98.0 \%$ (Figure 8c).

The most recent Holocene (Figure $8 \mathrm{~d}$ ) is characterized by four millennial-scale ( $\mathrm{TO}_{\mathrm{K} 1500 \mathrm{~V}}$ ) cycles culminating in temperature maxima followed immediately by temperature minima (e.g., $\mathrm{TO}_{\mathrm{C} 350 \mathrm{~V}}$ cycles \# 24, 18, 13 and 4). These cycles are evident to variable degrees across all four of the AICC2012-synchronized climate records (Figure 8d). In contrast to the pre-Holocene and early 
Holocene, however, the $\mathrm{TO}_{\mathrm{C} 350 \mathrm{~V}}$ cycle peaks occur nearly simultaneously at different drill sites, i.e., the mean peak-to-peak latencies between identified $\mathrm{TO}_{\mathrm{C} 350 \mathrm{~V}}$ cycles at different drill sites approach zero. The reversal of latencies seen in the early Holocene (i.e., the shift from Vostok-lags to Vostok-leads) is absent, particularly for the most recent two millennia of the Holocene. Corresponding peak-to-peak latencies are less than the summed variance of averaging and chronological uncertainty. The warmest portion of the paleoclimate record analyzed here is, therefore, also characterized by the closest synchrony of homologous $\mathrm{TO}_{\mathrm{C} 350 \mathrm{~V}}$ cycles, which may provide clues about the mechanism of regional propagation of the ACO as discussed below. Cycle coherency over the recent Holocene is $100 \%$ across all cycles, signpost and non-signpost (Figure 8d).

\subsection{ACO Period}

Mean $\mathrm{TO}_{\mathrm{C} 350 \mathrm{~V}}$ cycle period computed from Vostok temperature-proxy data is 352 years over the $226.4 \mathrm{Ky}$ time period evaluated, ranging from 63 to 1174 years (Table 1). The decrease in cycle period over time shown qualitatively in the time series of Figure 1 is confirmed quantitatively in Figure 9. Over the $226.4 \mathrm{Ky}$ analyzed, $\mathrm{TO}_{\mathrm{C} 350 \mathrm{~V}}$ cycle period declined by $\sim 100 \%$ on average from approximately 500 to 250 years (Figure $9 \mathrm{a}$ ). By the end of the Holocene $\mathrm{TO}_{\mathrm{C} 350 \mathrm{~V}}$ cycle period declined on average to less than 100 years. Mean ACO period for the 325 cycles from 88,196 to 0.149 Kyb1950 (mean 295.9 years) is discernibly smaller than the mean ACO period for the 325 cycles from 226.4 to $88.196 \mathrm{Kyb} 1950$ (mean 423.7 years) ( $t$-test, $p<0.00001$ ). This long-term change in TOC350V cycle frequency is not attributable to variance from frequency aliasing, which is estimated as $<0.5 \%$ (SM). Neither is this long-term change in $\mathrm{TO}_{\mathrm{C} 350 \mathrm{~V}}$ cycle frequency attributable to variable sample resolution, which changes only slightly over long portions of the record (SM, Figure S2) while ACO frequency increases both systematically and episodically over the same time periods (Figure 9a).

Table 1. Descriptive statistics for $\mathrm{TO}_{\mathrm{C} 350 \mathrm{~V}}$ climate cycles computed from 226.4 to $0.149 \mathrm{Kybp}$.

\begin{tabular}{|c|c|c|c|c|c|c|c|c|}
\hline Statistic & Period (Years) & $\begin{array}{l}\text { Amplitude } \\
\left({ }^{\circ} \mathrm{C}\right)\end{array}$ & $\begin{array}{c}\text { Warming } \\
\text { Duration } \\
\text { (Years) }\end{array}$ & $\begin{array}{c}\text { Cooling } \\
\text { Duration } \\
\text { (Years) }\end{array}$ & $\begin{array}{c}\text { Warming } \\
\text { Amplitude } \\
\left({ }^{\circ} \mathrm{C}\right)\end{array}$ & $\begin{array}{c}\text { Cooling } \\
\text { Amplitude } \\
\left({ }^{\circ} \mathrm{C}\right)\end{array}$ & $\begin{array}{l}\text { Warming Rate } \\
\left({ }^{\circ} \mathrm{C} / \text { Century }\right)\end{array}$ & $\begin{array}{l}\text { Cooling Rate } \\
\left({ }^{\circ} \mathrm{C} / \text { century }\right)\end{array}$ \\
\hline Mean & 352 & 0.67 & 184 & 189 & 0.66 & 0.68 & 0.43 & 0.44 \\
\hline Min & 63 & 0.05 & 19 & 28 & 0.01 & 0.01 & 0.01 & 0.01 \\
\hline Max & 1174 & 3.22 & 713 & 861 & 3.09 & 3.46 & 5.00 & 4.52 \\
\hline$\sigma$ & 175 & 0.44 & 109 & 114 & 0.53 & 0.52 & 0.46 & 0.45 \\
\hline CV & 0.50 & 0.66 & 0.59 & 0.60 & 0.79 & 0.77 & 1.07 & 1.03 \\
\hline SS $(n)$ & 646 & 546 & 546 & 546 & 546 & 546 & 546 & 546 \\
\hline
\end{tabular}

$\mathrm{TO}_{\mathrm{C} 350 \mathrm{v}}$ cycle statistics computed from the data contained in SM Table S1 for the Vostok ice-core record (GT4 glaciological chronology) $[36,37]$. Period was computed using all three definitions of a TO C350v cycle. Remaining statistics were computed using the more restrictive first two definitions (SM, 2. Methods). Abbreviations: Min, minimum; Max, maximum; $\sigma$, standard deviation of the mean; $\mathrm{CV}$, coefficient of variation (standard deviation divided by the mean); SS (n), sample for same column.

The ACO is locked in phase with the integrated $41 \mathrm{Ky}$ orbital Obliquity/Precession Orbital Cycle or OPOC [6,7] (Figure 9a). Peaks in $\mathrm{TO}_{\mathrm{C} 350 \mathrm{~V}}$ cycle period occur in approximate phase with insolation minima at $65^{\circ} \mathrm{N}$ computed from the OPOC. Plotting the time series of cycle period for every $\mathrm{TO}_{\mathrm{C} 350 \mathrm{v}}$ cycle (Figure $9 \mathrm{~b}$ ) shows large, short-term or episodic fluctuations in $\mathrm{TO}_{\mathrm{C} 350 \mathrm{v}}$ period. High-frequency (short-period) bursts of $\mathrm{TO}_{\mathrm{C} 350 \mathrm{v}}$ cycles occur during the warm interstadials identified by odd-numbered MISs (Figure 9b), while low-frequency (long-period) $\mathrm{TO}_{\mathrm{C} 350 \mathrm{~V}}$ cycles occur during the intervening cold stadials. Differences between stadial and interstadial $\mathrm{TO}_{\mathrm{C} 350 \mathrm{~V}}$ cycle period for individual cycles approach $800 \%$. These findings are consistent with the hypothesis that ACOs exhibit relatively high sensitivity to ambient temperature. 


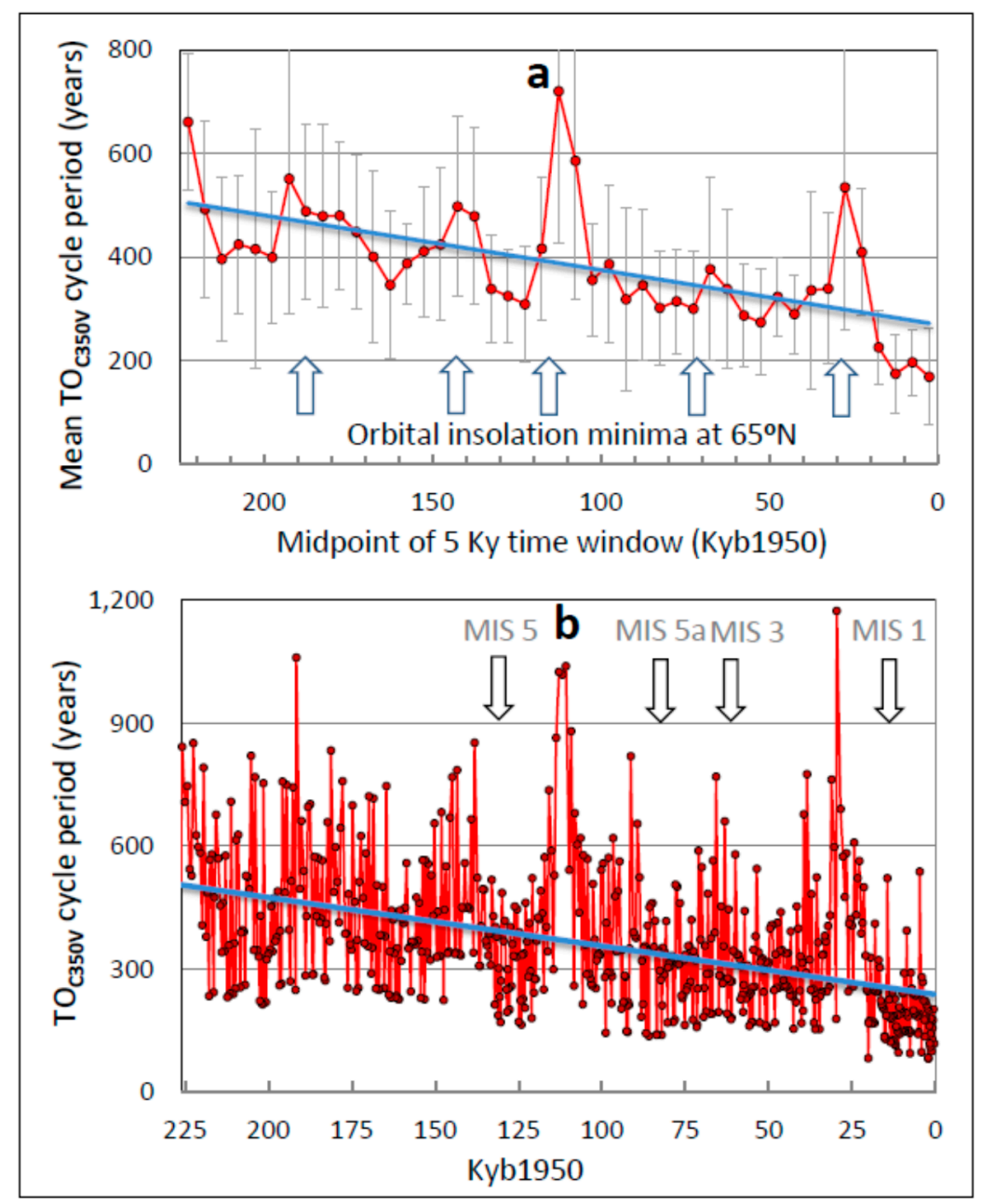

Figure 9. Period of ACOs over the last 226.4 Ky of the Vostok climate record. These graphs illustrate the steady decline of period over 226 millennia (a) and episodic decreases in period associated with the warming phase of Marine Isotope Stages (MISs, or glacial cycles) (b). (a) period averaged in five Ky bins. (b) unaveraged period across individual $\mathrm{TO}_{\mathrm{C} 350 \mathrm{~V}}$ cycles. The vertical bars in (a) denote $\pm 1 \sigma$ for each mean datapoint (mean sample size per datapoint, $\sim 15$ ). The trendline is fitted by the method of least squares. The vertical arrows in (a) signify insolation minima at $65^{\circ} \mathrm{N}$ associated with the integrated Obliquity/Precession Orbital Cycle (OPOC) [6,7] and are accompanied by peaks in $\mathrm{TO}_{\mathrm{C} 350 \mathrm{~V}}$ period. ACO period is graphed cycle-by-cycle in (b). The times of onset of Marine Isotope Stages (MISs) are marked by arrows following the timing reported by Lisiecki and Raymo [5]. $n=650$, incorporating all three $\mathrm{TO}_{\mathrm{C} 350 \mathrm{v}}$ cycle definitions.

$\mathrm{TO}_{\mathrm{C} 350 \mathrm{v}}$ cycle period declines to near its lowest sustained level by the Holocene, a trend that continues and accelerates up to and throughout the $\mathrm{CE}$. High-frequency $\mathrm{TO}_{\mathrm{C} 350 \mathrm{~V}}$ cycles continue up to the $\mathrm{CE}$, where $\mathrm{TO}_{\mathrm{C} 350 \mathrm{v}}$ cycles oscillate at a higher frequency than at any time during the previous 226.4 millennia (Figures 1 and 9b). These observations confirm directly the decrease in cycle period (increase in cycle frequency) that is evident visually in climate record time series (e.g., Figure 1) and is shown by spectral analysis of different time periods of the same climate records (Figures $2-4$ and 7). These findings also demonstrate that the climate signals corresponding to ACOs cannot be attributed to "noise" except under the circular reductio ad absurdum that MIS cycles and corresponding orbital forces modulate noise in climate records to yield statistically-discernible variations, in which case they do not conform to the definition of noise. 


\subsection{ACO Amplitude}

The mean amplitude of $\mathrm{TO}_{\mathrm{C} 350 \mathrm{~V}}$ cycles computed from Vostok data is $0.67^{\circ} \mathrm{C}$ over the 226.4 time period evaluated, ranging from $0.05-3.22{ }^{\circ} \mathrm{C}$ (Table 1). The increase in $\mathrm{TO}_{\mathrm{C} 350 \mathrm{~V}}$ cycle amplitude suggested qualitatively by the time series of the last $20 \mathrm{Ky}$ (Figure 1) is confirmed quantitatively for the entire 226.4 period of this analysis (Figure 10). Over this time period $\mathrm{TO}_{\mathrm{C} 350 \mathrm{v}}$ cycle amplitude increased by approximately two-thirds, from 0.52 to $0.82{ }^{\circ} \mathrm{C}$ (Figure 10a) in parallel with the decline in $\mathrm{TO}_{\mathrm{C} 350 \mathrm{~V}}$ cycle period described above (Figure 9). By the end of the Holocene, centennial cycle amplitude routinely approached $2-3{ }^{\circ} \mathrm{C}$. The average cycle amplitude of the 273 cycles that occurred from 226.4 to $88.196 \mathrm{Kyb} 1950\left(0.62{ }^{\circ} \mathrm{C}\right)$ is discernibly smaller than the average cycle amplitude of the 273 cycles that occurred from 88.196 to $0.149 \mathrm{Kyb} 1950\left(0.72{ }^{\circ} \mathrm{C}\right)(t$-test, $p<0.000025)$, i.e., amplitude increased discernibly across the two time periods. The increase in $\mathrm{TO}_{\mathrm{C} 350 \mathrm{~V}}$ cycle amplitude is not attributable to changes in sample resolution, which remained relatively stable as cycle amplitude increased over the same time periods (cf. Figure 10a with SM Figure S2).

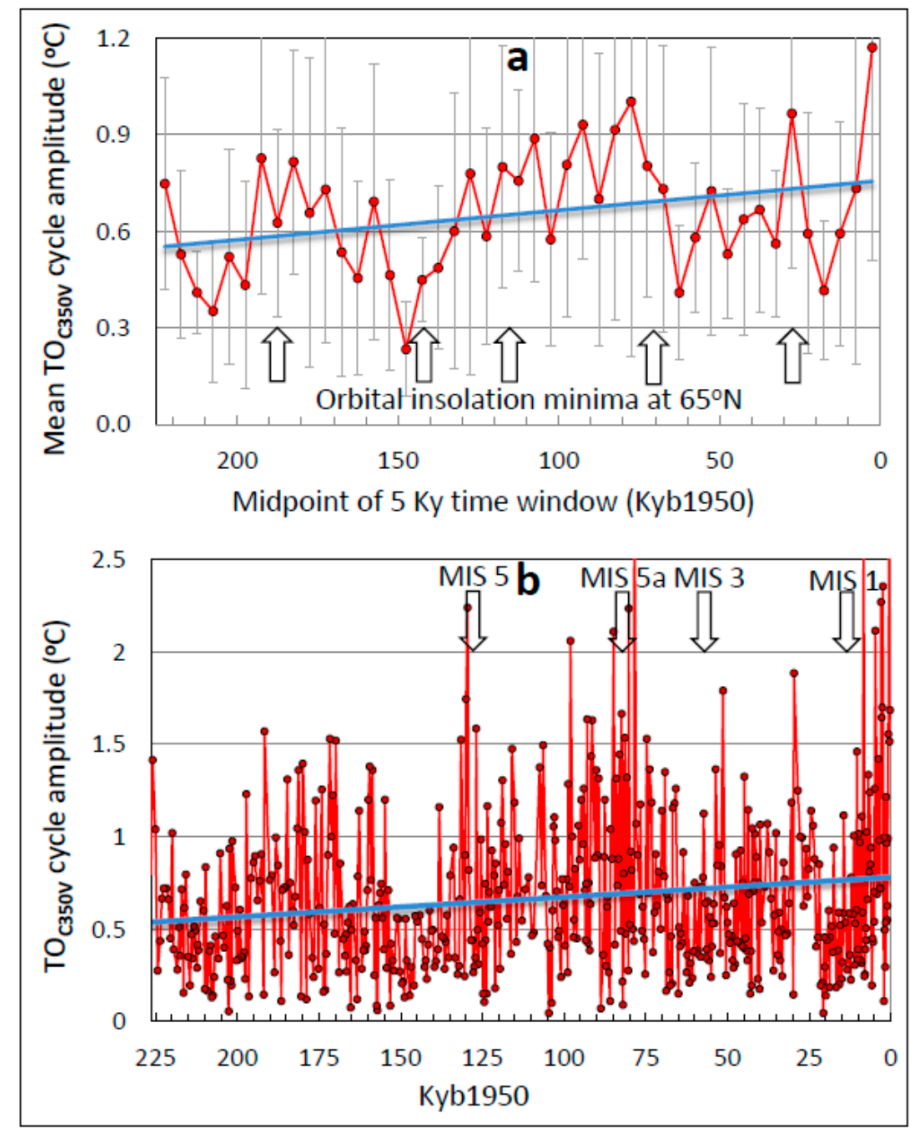

Figure 10. Amplitude of ACOs over the last 226.4 Ky of the Vostok climate record. The amplitude of $\mathrm{TO}_{\mathrm{C} 350 \mathrm{~V}}$ cycles increases steadily over 226 millennia (a) while episodic increases in amplitude are associated with the warming phase of Marine Isotope Stages (MISs) or glacial cycles (b). $n=546$, incorporating cycle definitions 1 and 2 only. Error bars in (a) correspond to $\pm 1 \sigma$.

The increase in $\mathrm{TO}_{\mathrm{C} 350 \mathrm{~V}}$ cycle amplitude over 226.4 millennia is not uniform. Peaks in cycle amplitude occur in approximate antiphase with surface insolation minima at $65^{\circ} \mathrm{N}$ that result from planetary orbital cycles (Figure 10a; orbital parameters are from [6,7]). Plotting the time series of cycle amplitude over every $\mathrm{TO}_{\mathrm{C} 350 \mathrm{~V}}$ cycle (Figure 10b) rather than in five Ky averages (Figure 10a) reveals large, short-term episodic fluctuations in $\mathrm{TO}_{\mathrm{C} 350 \mathrm{~V}}$ amplitude. Peaks in $\mathrm{TO}_{\mathrm{C} 350 \mathrm{~V}}$ cycle amplitude occur during warm interstadials associated with odd-numbered MISs (Figure 10b), when cycle 
period is smallest (Figure 9). Troughs in centennial-cycle amplitude occur during cold stadials corresponding to even-numbered MISs (Figure 10b), when cycle period is largest (Figure 9). The ratio of interstadial-to-stadial $\mathrm{TO}_{\mathrm{C} 350 \mathrm{~V}}$ amplitude exceeds 60 , suggesting that $\mathrm{TO}_{\mathrm{C} 350 \mathrm{~V}}$ cycle amplitude is not only more variable than cycle frequency, but also several times more sensitive to temperature. $\mathrm{TO}_{\mathrm{C} 350 \mathrm{~V}}$ cycle amplitude increases to its highest sustained level, $2-3{ }^{\circ} \mathrm{C}$, during the Holocene and particular during the last millennium (Figures 1 and 10b). These findings confirm directly the increase in cycle amplitude suggested in time series (e.g., Figure 1).

\subsection{Orbital Influences}

The period and amplitude of $\mathrm{TO}_{\mathrm{C} 350 \mathrm{~V}}$ cycles appears qualitatively to be synchronized with variations in surface insolation induced by the $41 \mathrm{Ky}$ integrated OPOC (Figures $9 \mathrm{a}$ and 10a respectively). To test this hypothesis quantitatively, the time series of cycle period and amplitude were plotted on the same time scale as the time series of the OPOC $[6,7]$ for the threshold glacial ablation insolation of $\tau=325 \mathrm{~W} / \mathrm{m}^{2}[6,7]$. ACO cycle period maximizes at the lowest $\mathrm{NH}$ insolation energies and minimizes during or near the highest NH insolation energies (Figure 11a). The lagged cross-correlation coefficients between insolation and $\mathrm{TO}_{\mathrm{C} 350 \mathrm{~V}}$ cycle period (Figure 11b) alternate between positive and negative at the OPOC frequency and are discernible, in peaks and troughs of the autocorrelelogram, at probabilities from $p<0.05$ to $p<10^{-10}$. $\mathrm{TO}_{\mathrm{C} 350 \mathrm{~V}}$ cycle period is therefore locked in approximate antiphase with the surface insolation cycle induced by the integrated OPOC, i.e., less insolation is associated with lower ACO repetition frequency. As anticipated from the relation between cycle period and amplitude (Figures 9 and 10), cycle amplitude also oscillates in approximate antiphase phase with surface insolation (Figure 12).

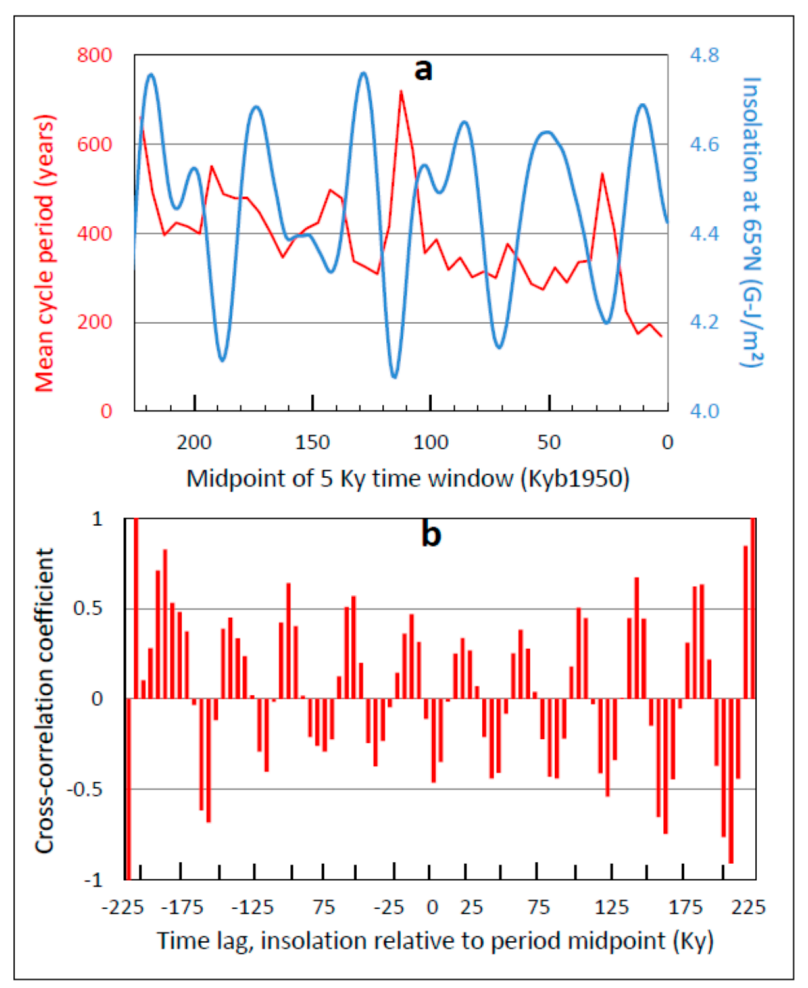

Figure 11. Orbital influences on ACO period over the last 226 millennia. The period of $\mathrm{TO}_{\mathrm{C} 350 \mathrm{~V}}$ cycles at Vostok versus summertime surface insolation at $65^{\circ} \mathrm{N}$ for a glacial ablation threshold $\tau=325$ (a) and corresponding lagged cross-correlelogram of cycle period versus insolation (b). These graphs demonstrate that $\mathrm{TO}_{\mathrm{C} 350 \mathrm{~V}}$ cycle period is coupled with the orbital cycle of solar insolation at $65^{\circ} \mathrm{N}[6,7]$. Cross-correlation coefficients in (b) oscillate at the orbital frequency and most are discernibly different from zero at $p<0.05$. Abbreviation: $\mathrm{G}-\mathbf{j}$, gigajoules. 


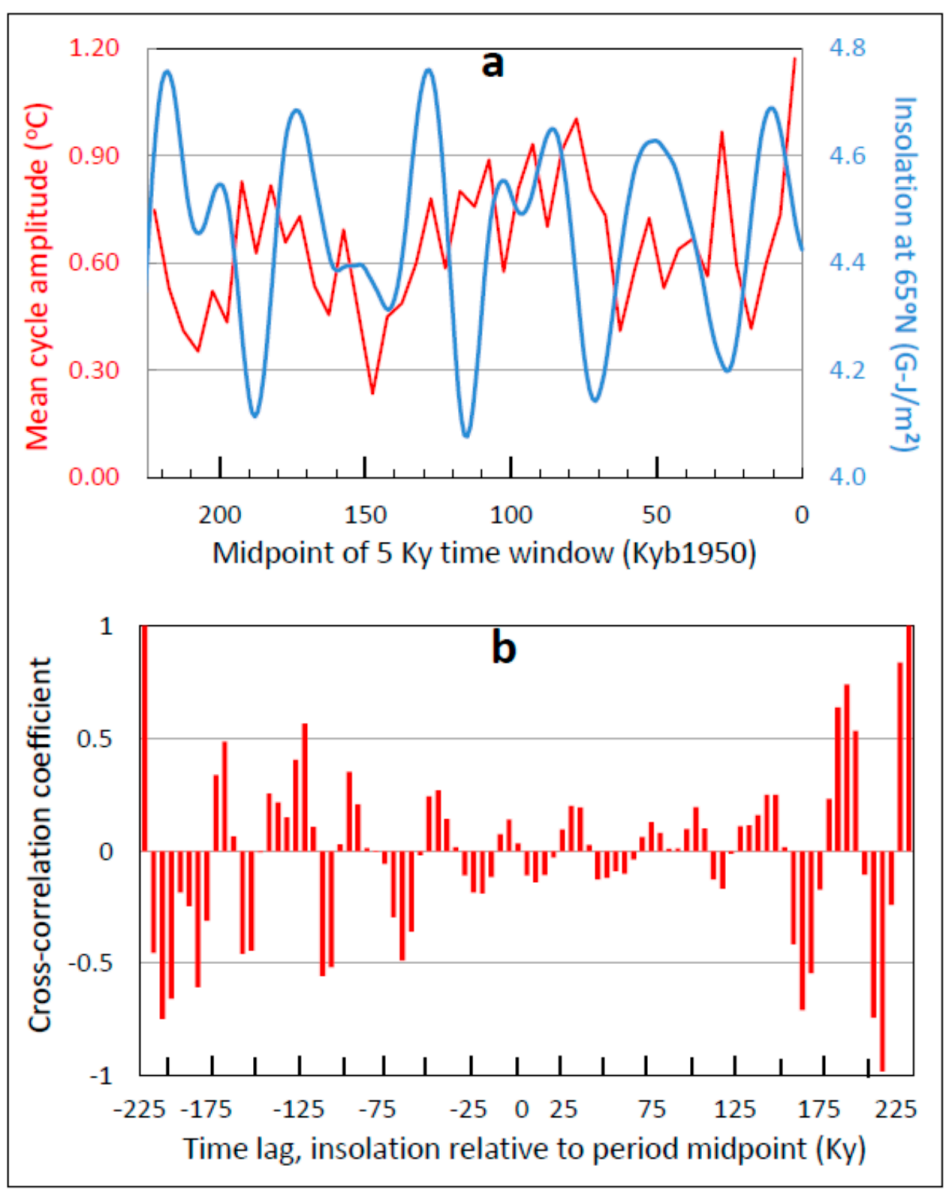

Figure 12. Orbital influences on ACO amplitude over the last 226 millennia. (a) ACO amplitude (red curve) on the same time scale as the Obliquity/Precession Orbital Cycle (OPOC) (blue curve). (b) cross-correlelogram of ACO amplitude versus the OPOC cycle.

\section{Discussion and Conclusions}

Centennial-scale climate cycles reported previously by several investigators $[33,40,52,56,57]$ and in this paper are significant in at least three contexts. First, centennial-scale climate cycles demonstrate "an important role of natural multicentennial variability that is likely to continue" [33] (p. 614). When both the mean and variance of any centennial-scale climate cycle are known, as is the case for the $\mathrm{TO}_{\mathrm{C} 350 \mathrm{v}}$ cycles documented here (Table 1), then the future behavior of such cycles can be projected within well-defined confidence limits. Understanding centennial-scale temperature cycles can therefore contribute to precise climate projections over timelines that are most pertinent to human and civilizational life cycles, decades to centuries. This approach to the projection of future climate change has been pioneered by Liu and colleagues [56] based on analysis of tree ring data from the Tibetan Plateau. From past centennial-scale temperature oscillations, they project a steep decline of temperature on the Tibetan Plateau of $\sim 3^{\circ} \mathrm{C}$ between 2006 and 2068, followed by a weaker warming trend and continuing on a cyclic basis into the future [56] (their Figure 5, p. 2292).

Second, centennial-scale paleoclimate cycles comprise a "natural" source of temperature forcing, i.e., one that is free from anthropogenic influences. Human impact on global climate from agriculture and land clearing may have begun as early as the mid-Holocene [58,59], but earlier climate change was presumably devoid of anthropogenic influences. Characterizing past cycles of temperature fluctuation can therefore help inform the distinction between natural (non-anthropogenic) and anthropogenic forcing of climate in the present, as discussed further below. 
Third, Antarctic temperature fluctuations on several time scales are reflected worldwide and in the NH after a delay of 0.5 to 3.0 millennia $[40,49,52,53,60-71]$. These delays were measured for older time periods, however, generally before the LGT, and may be shorter for more recent climate events in a warmer environment (see below). Given the close association between AIMs in the Antarctic and D-O events in the $\mathrm{NH}$, as demonstrated repeatedly by previous investigators $[38,40,49,52]$, the discovery here that AIMs are composed of summated $\mathrm{TO}_{\mathrm{C} 350 \mathrm{~V}}$ cycles constitutes strong evidence that ACOs manifest globally. The centennial-scale climate cycles identified in the $\mathrm{NH}[33,56,57]$ may be northerly manifestations of the Antarctic $\mathrm{TO}_{\mathrm{C} 350 \mathrm{~V}}$ climate cycle documented here, a hypothesis that remains to be tested. In the meantime, the present findings demonstrate that the ACO and its potential modern counterpart (the AAO; see below) influence the temperature of the $\mathrm{NH}$. This finding suggests a potentially-fruitful research direction aimed at assessing the impact of the contemporary AAO on global climate and weather. Our study raises the possibility that the ACO/AAO entrains global temperature and serves as the primary pacemaker of centennial fluctuations in temperature in both hemispheres while simultaneously modulating shorter cycles.

\subsection{Geographic Distribution of ACO Cycles}

Comparison of $\mathrm{TO}_{\mathrm{C} 350 \mathrm{v}}$ cycles across the four AICC2012-synchronized climate records evaluated here supports four conclusions and interpretations. First, spectral density peaks from the Vostok paleoclimate record since the LGM are matched $( \pm 2.4 \%)$ with peaks from other EAP climate records synchronized on the AICC2012 chronology. In addition, 100\% of signpost cycles and more than $98 \%$ of all single, individual $\mathrm{TO}_{\mathrm{C} 350 \mathrm{~V}}$ cycles evaluated at Vostok match one-to-one with homologs at the three other drill sites evaluated here and conversely. Therefore, $\mathrm{TO}_{\mathrm{C} 350 \mathrm{~V}}$ cycles occur at all four AICC2012-synchronized drill sites on the EAP despite the separation of the sites by up to thousands of $\mathrm{km}$ and elevation differences of up to more than a kilometer [51].

Second, the time latencies between the peaks of individual, identified $\mathrm{TO}_{\mathrm{C} 350 \mathrm{v}}$ signpost cycles in different climate records ("homologs") varied systematically by up to several centuries. These latencies exceed reported variance arising from dating uncertainty in the AICC2012 chronology by up to nearly 40-fold, and therefore cannot be ascribed to chronological uncertainty or "noise". Prior to the LGT, identified $\mathrm{TO}_{\mathrm{C} 350 \mathrm{~V}}$ cycles are detectable first at TD and EDML and appear centuries later at EDC and Vostok. In this limited sample of four drill sites, therefore, the locations where $\mathrm{TO}_{\mathrm{C} 350 \mathrm{v}}$ cycles can first be detected (TD and EDML) are closer to the ocean, lower in elevation, warmer and wetter than those where homologous $\mathrm{TO}_{\mathrm{C} 350 \mathrm{~V}}$ cycles occur centuries later on the higher, drier and colder EAP (EDC and Vostok). This timing sequence encourages future research directions on the origin of $\mathrm{TO}_{\mathrm{C} 350 \mathrm{~V}}$ cycles in which the sample is expanded to the eleven best-studied Antarctic drill sites to evaluate propagation latencies and directions using a larger sample size. Backward extrapolation of these cycle parameters may pinpoint the geographic origin of the ACO cycle.

Third, the measured latencies between peaks of homologous $\mathrm{TO}_{\mathrm{C} 350 \mathrm{~V}}$ cycles at different drill sites vary and reverse on short (centennial) time scales. Before the LGT, $\mathrm{TO}_{\mathrm{C} 350 \mathrm{~V}}$ cycle homologs across the climate records evaluated here were asynchronous, but after the LGT and during the warmer Holocene, homologous $\mathrm{TO}_{\mathrm{C} 350 \mathrm{~V}}$ cycles became synchronous, i.e., the latency of homologous ACOs at different sites approached zero. Some of the reduction in latency between homologous cycles at different drill sites is expected from the observed increase in cycle frequency over time and the consequent compression of individual cycles. Most of the change in latency, however, arises from genuine (non-artifactual) differences in the arrival time of homologous $\mathrm{TO}_{\mathrm{C} 350 \mathrm{~V}}$ cycle peaks at different drill sites. As noted, this difference in latencies typically exceeds chronological uncertainty in the AICC2012 climate records studied here by more than an order of magnitude. This finding supports the hypothesis that the propagation velocity of ACOs increases with temperature, which in turn bears upon the mechanism(s) of regional cycle teleconnection that remain to be investigated.

Fourth, comparison of homologous $\mathrm{TO}_{\mathrm{C} 350 \mathrm{~V}}$ cycles across four Antarctic climate records reveals a "climate memory" in Antarctica, reflected in the conservation of centennial cycle architecture between 
homologous cycles at different drill sites as $\mathrm{TO}_{\mathrm{C} 350 \mathrm{~V}}$ cycles propagate across Antarctica. The transition from asynchrony to synchrony of $\mathrm{TO}_{\mathrm{C} 350 \mathrm{~V}}$ cycle homologs during the most recent glacial termination and the Holocene suggests that this climate memory fades and disappears with rising temperature. The mechanism(s) of this climate memory are unknown, but a plausible candidate is hysteresis in the temperature/ice system, since these components of the Antarctic climate exhibit the prerequisite long time constants and temperature sensitivity [9].

\subsection{Relation of the ACO to Contemporary Climate Cycles}

The $\mathrm{TO}_{\mathrm{C} 350 \mathrm{~V}}$ climate cycle documented in this study for the past 226.4 millennia presumably continues to oscillate into the present. The most likely contemporary candidate for such a comparison between past and present manifestations of the ACO is the interrelated AAO/SAM/SOI cycle (Introduction). The geographic scope and repetition period of this contemporary climate oscillation is similar to $\mathrm{TO}_{\mathrm{C} 350 \mathrm{~V}}$ cycles over the recent Holocene, and to our knowledge there is no other tenable candidate for this comparison in the $\mathrm{SH}$ based on the geographic scope or the oscillatory period of known contemporary climate cycles.

This hypothesis receives support from the observation that the $\mathrm{TO}_{\mathrm{C} 350 \mathrm{~V}}$ cycles identified here are similar in period and relative amplitude to comparable cycles of the AAO that have been identified independently from more contemporary tree-ring data [26,27] and from stacked temperature-proxy records from Vostok snow pits [32]. Similarly, westerly wind records in the SH (Falkland Islands) for the past 2600 years as assessed from records of pollen distribution show discernible AAO spectral peaks at 242, 185, 150 and 95 years that average 168 years [72] (Figure 5a, p. 194), similar to the 193-year discernible peak in the Holocene spectral periodogram of the ACO (Figure 3) and the 162-year average period over the last 2,600 years (Figure 1d). We therefore conclude, subject to confirmatory research, that the ACO is the probable paleoclimate precursor of, and is continued into the present by, the contemporary Antarctic Oscillation (AAO/SAM/SOI).

\subsection{Intensification of the Antarctic Climate}

The demonstration here that $\mathrm{TO}_{\mathrm{C} 350 \mathrm{~V}}$ cycles increased in frequency and amplitude over hundreds of millennia indicates that temperature fluctuations in the Antarctic have become more frequent, rapid, and extreme over geologic time, i.e., the ACO has strengthened during the 226-millenium time period encompassed by this study. Similarly, the comparison here of spectral periodograms corresponding to different time periods suggests that the $\mathrm{TO}_{\mathrm{K} 1500 \mathrm{~V}}$ cycle declined in period by $\sim 50 \%$ over the past 70 millennia, from about 1500 years to 800 years. This millennial cycle oscillates at the same frequency as the AIMs known to precede D-O events in the $\mathrm{NH}[23,38]$. These findings support the hypothesis that the Antarctic climate is dynamic and has intensified by a factor of two over the past 226 millennia. The strengthening of the Antarctic climate has implications for contemporary and future regional and global climate as discussed further below.

These findings show that contrary to past assumption, climate cycles such as the ACO and the millennial-scale $\mathrm{TO}_{\mathrm{K} 1500 \mathrm{~V}}$ cycle that paces AIMs do not comprise stationary time series. This conclusion has implications both for analytic methodologies that can be brought to bear on climate data and also for the interpretation of natural versus anthropogenic influences as discussed below. In respect to the methodological issues, many analytic approaches to climate data are based on the assumption of linearity and a stationary time series. Spectral analysis, for example, which is based on Fourier transformation, is technically applicable only to stationary time series. Our study shows that climate data do not necessarily comprise a stationary time series, yet spectral analysis is used almost universally in climate science, including in most of the references we cite here (e.g., [2] (Figure 12, p. 123), [3] (Figures 7 and 10), [4] (Figure 4, p. 689), [5] (Figure 12, p. 14), [6] (Figure 2b,d,f, p. 509), etc. Our study suggests the need for a comprehensive expert review of methodological approaches to the analysis of climate data in view of potential non-stationarity. 
The dilemma for the present work is that we used standard techniques of climate science in a study whose results show that these techniques may not be well-suited to climate data. This dilemma constitutes a limitation of this study. We believe that this limitation is minor because we evaluated primarily relatively short segments of the climate record, which comprise relatively stationary time series as demonstrated by strongly-positive auto- and cross-correlation results. At the same time, our study suggests that it would now be fruitful to apply the more reliable and modern methods of Wavelet Analysis, Empirical Mode Decomposition, Hilbert-Huang Transforms, etc., to the climate data analyzed here. These data are presented in full in the SM Table S1 for exactly such purposes.

The increase in frequency over time of both the $\mathrm{TO}_{\mathrm{C} 350 \mathrm{~V}}$ and $\mathrm{TO}_{\mathrm{K} 1500 \mathrm{~V}}$ cycles found here in the Antarctic may help resolve the debate over the oscillatory period of related Greenland Interstadials (GIs) including both Heinrich events and D-O oscillations [22,23]. In particular, the 1470-year cycle period of D-O events (GIs) in Greenland [20] has been characterized as "potentially an artifact of arithmetic averaging" [23] (p. 23). Our finding here that the repetition period of a comparable cycle in the Antarctic (the $\mathrm{TO}_{\mathrm{K} 1500 \mathrm{~V}}$ cycle) declines from 1500 to 800 years over the last $70 \mathrm{Ky}$ suggests an alternative explanation, namely, that spectral peaks of climate oscillations in the $\mathrm{NH}$ represent discrete steps in a variable, non-stationary time series composed of several discernible spectral density peaks that nonetheless originate from a single, variable millennial-scale climate cycle. This proposal is consistent with the discovery of several statistically-discernible spectral peaks in Greenland ice core data ranging from 1500 to 800 years, the same range found here in the $\mathrm{SH}$ for the last $70 \mathrm{Ky}$, and which have also been attributed in part to a non-stationary time series [23].

\subsection{Climate Stability and the Origin of D-O Oscillations}

Rapid fluctuations in temperature-proxy records during the Holocene and earlier have long been interpreted as indicators of an unstable and chaotic global climate ([16,73-76] and references therein). In contrast, our study shows that such temperature-proxy fluctuations comprise a well-defined, predictable, centennial-scale climate oscillation with quantifiable descriptive statistics (Table 1). These cycles vary systematically with multi-millennial glacial cycles (MISs) and with related and presumably causal planetary orbital forces (the integrated OPOC), or Milankovitch cycles, and therefore cannot be attributed to "noise". It appears, therefore, that the observed temperature-proxy fluctuations over the past hundreds of millennia do not imply instability of a chaotic global climate, but are indicative instead of exactly the opposite-a highly stable and predictable climate consisting of systematic changes in temperature that follow quantified oscillatory parameters, namely a centennial climate cycle that interacts with a millennial climate cycle as documented here.

Dansgaard-Oeschger (D-O) events in the $\mathrm{NH}$, for example, recently termed Greenland Interstadials or GIs [23], have been portrayed as exemplars of climate instability [16] and "abrupt climate change" [77]. D-O events manifest in Greenland ice cores as a periodic sudden (decadal) and "runaway" (positive feedback) exponential warming of several ${ }^{\circ} \mathrm{C}$ followed by a longer and more linear cooling recovery. Computer simulations have been interpreted to imply that such a sudden change in climate "inherently limits [climate] predictability" [77] (p. 111). In contrast to this interpretation, the empirical analysis reported here shows that demonstrated precursors to D-O (GI) events in the Antarctic, namely AIMs, are composed of several $\mathrm{TO}_{\mathrm{C} 350 \mathrm{~V}}$ cycles that recur in rapid succession at the highest observed $\mathrm{TO}_{\mathrm{C} 350 \mathrm{~V}}$ repetition frequencies, driven by the $\mathrm{TO}_{\mathrm{K} 1500 \mathrm{~V}}$ cycle. These $\mathrm{TO}_{\mathrm{C} 350 \mathrm{~V}}$ cycles add together over time (summate) with millennial periodicity to form AIMs, manifesting the $\mathrm{TO}_{\mathrm{K} 1500 \mathrm{~V}}$ cycle which was identified previously in the $\mathrm{NH}$ as the Bond cycle [17-21]. The only prerequisite for such "temporal summation" of $\mathrm{TO}_{\mathrm{C} 350 \mathrm{~V}}$ cycles in the $\mathrm{SH}$ is their recurrence at a sufficiently high frequency to ensure that one $\mathrm{TO}_{\mathrm{C} 350 \mathrm{~V}}$ cycle begins before the preceding cycle ends, so that successive ACOs "piggyback" on one another to create a larger AIM.

Central to this interpretation, and as noted above, AIMs in the SH have been established by several previous investigators as precursors of D-O (GI) events in the NH $[38,40,49,52]$. Each AIM precedes its corresponding D-O (GI) event in the NH by 1.5-3.0 millennia [40], linked by hemispheric 
teleconnection that has been attributed to the bipolar climate see-saw [40], although this teleconnection time may be smaller in the more recent Holocene (see below). The discovery here that AIMs are composed of identifiable $\mathrm{TO}_{\mathrm{C} 350 \mathrm{~V}}$ cycles that maximize periodically, paced by the $\mathrm{TO}_{\mathrm{K} 1500 \mathrm{~V}}$ cycle in the $\mathrm{SH}$, provides a novel yet straightforward hypothesis for the origin of $\mathrm{D}-\mathrm{O}(\mathrm{GI})$ oscillations in the $\mathrm{NH}$. By this hypothesis, temporally-summated $\mathrm{TO}_{\mathrm{C} 350 \mathrm{~V}}$ cycles generate AIMs in the $\mathrm{SH}$ with millennial periodicity, following the $\mathrm{TO}_{\mathrm{K} 1500 \mathrm{~V}}$ cycle, and these AIMs in turn teleconnect by undemonstrated mechanisms to the $\mathrm{NH}$, where they induce $\mathrm{D}-\mathrm{O}(\mathrm{GI})$ events.

It follows that D-O (GI) events are neither attributable to nor diagnostic of climate "instability", but are instead caused by systematic and predictable interactions between centennial-scale oscillatory climate cycles in Antarctica that are modulated on a variable millennial time scale in phase with the $\mathrm{TO}_{\mathrm{K} 1500 \mathrm{~V}}$ cycle. This hypothesis implies that abrupt millennial-scale climate changes such as D-O (GI) events, and more gradual natural climate change on centennial scales, are inherently and precisely predictable. This conclusion in turn imparts new statistical power to projections of future climate, as exemplified by the work of Liu et al. [56]. This hypothesis can be tested potentially by examining counterparts to $\mathrm{TO}_{\mathrm{C} 350 \mathrm{v}}$ cycles in the $\mathrm{NH}$, which is however beyond the scope of the present study.

\subsection{Implications for Contemporary Global Warming}

Recent changes in the AAO/SAM toward the most positive (meridionally-contracted) phase seen in several centuries have been attributed to increased atmospheric concentrations of anthropogenic greenhouse gases [26,27]. This conclusion assumes, however, that "natural" (non-anthropogenic) climate change comprises a stationary time series, enabling potential anthropogenic forcing signals to emerge from a flat "natural" baseline [78]. This assumption is falsified by the findings of the present study, which show that the frequency and the amplitude of $\mathrm{TO}_{\mathrm{C} 350 \mathrm{~V}}$ cycles increased together over the last 226.4 millennia and also on a regular millennial schedule. Comparative spectral analysis of different time periods reported here suggests a similar conclusion for the $\mathrm{TO}_{\mathrm{K} 1500 \mathrm{~V}}$ cycle.

The conclusion that Antarctic climate cycles increase in intensity over time and, therefore, do not comprise a stationary time series, has implications for understanding human impacts on the global climate. During most of the 226 millennia evaluated in the present study, humans exerted little or no influence on climate. The evolution of the SAM toward its most positive phase in several centuries during the last millennium may therefore result from the "natural" (non-anthropogenic) intensification of the Antarctic climate documented in this study, perhaps following the pattern identified here of millennial-scale increases in amplitude and frequency of ACOs terminated by a single large temperature peak and trough.

Consistent with this conclusion, it has been reported recently that natural variability in Antarctic temperature "overwhelms" any possible anthropogenic forcing of temperature for at least the past two centuries [79] (p. 917). In this case, and assuming that the ACO is the climatic precursor of the AAO, it may be concluded that the recent changes in the AAO toward the most positive phase seen in several centuries result not from increased atmospheric concentrations of anthropogenic greenhouse gases [26,27], but rather from the natural increases in amplitude and frequency of the ACO as documented in the present study.

The finding here of a natural climate cycle that oscillates on a centennial scale and impacts temperature in the $\mathrm{NH}$ has further implications for the debate about anthropogenic global warming (AGW). It has been considered widely that atmospheric carbon dioxide $\left(\mathrm{CO}_{2}\right)$ emitted by human activities is responsible for the contemporary global warming signal. Recent research shows, however, that neither atmospheric $\mathrm{CO}_{2}$ nor marginal radiative forcing by $\mathrm{CO}_{2}$ is generally correlated discernibly with global temperature over the past 425 million years [3]. Therefore, neither atmospheric $\mathrm{CO}_{2}$ nor marginal radiative forcing by $\mathrm{CO}_{2}$ caused temperature change in the ancient climate [3]. The same study showed that contemporary marginal radiative forcing by atmospheric $\mathrm{CO}_{2}$ has declined by approximately two-thirds since the beginning of the Industrial Age owing to the well-known logarithmic relationship between radiative forcing and atmospheric $\mathrm{CO}_{2}$ concentration [3]. 
Progressively larger concentrations of atmospheric $\mathrm{CO}_{2}$ therefore yield progressively smaller global temperature change, minimizing any possible impact of $\mathrm{CO}_{2}$ on global temperature.

A primary rationale for invoking anthropogenic emissions of $\mathrm{CO}_{2}$ as the cause of contemporary global warming has been the perceived lack of alternative explanations, particularly the absence of a natural climate cycle that might account for the current global warming signal of $\sim 0.8^{\circ} \mathrm{C}$ since 1850. The 2017 US Global Change Research Program Report on climate [41] concluded, for example, that "For the warming over the last century, there is no convincing alternative explanation supported by the extent of the observational evidence" [41] (p. 12). The empirical documentation here of a natural paleoclimate climate cycle that impacts temperature in the $\mathrm{NH}$ and that is probably homologous with the contemporary AAO, namely, the ACO, provides such a possible alternative explanation. By this alternative explanation, the global temperature profile since 1850 is caused in whole or part by a natural climate cycle (the ACO/AAO) that is approaching or has reached its temperature peak. The peaking of this natural warming cycle would also explain the recorded deceleration of warming over the last two decades, termed the "warming hiatus" [80-82].

A key falsifying test of this "natural global warming" (NGW) hypothesis as a viable alternative to the AGW hypothesis revolves around timing. The last millennium at Vostok has encompassed eight ACO cycles, whose average period is, therefore, 125 years (Figure 1 and SM Table S1). The most recent recorded temperature peak at Vostok occurred in 1760. Incrementing this date by the average ACO period of 125 years over the past millennium projects ACO peaks at Vostok in 1885 and 2010. The latter date is consistent with the possible peaking of the contemporary global warming trajectory in the $\mathrm{NH}$, assuming acceleration of $\mathrm{ACO}$ teleconnection velocities with increasing temperature as we suggest here for regional teleconnection within the SH. Pedro and colleagues have also reported that changes in Antarctic and Greenland climate occur with "little-to-no time lag between climate transitions" [53] (p. 671), consistent with the hypothesis that the ACO influences NH temperature with vanishingly-small latency in the recent paleoclimate record (the late Holocene). Similarly, "climate changes at Taylor Dome during the last glacial-interglacial transition were synchronous or near synchronous with changes in the North Atlantic region" [62] (p. 94).

This analysis of timing remains simplistic and preliminary in that it does not account for variance in ACO period and amplitude nor measured teleconnection times, but it nonetheless demonstrates to a first approximation that the ACO, in its proposed modern form of the AAO, is a plausible candidate for the source of contemporary global warming. This NGW hypothesis merits and requires further research as an alternative to the AGW hypothesis. As established by previous research [3], however, the possibility that contemporary global warming results from a natural climate cycle, rather than from anthropogenic emissions of $\mathrm{CO}_{2}$, may not lessen the urgency to consider limiting anthropogenic $\mathrm{CO}_{2}$ emissions. Peaks in atmospheric $\mathrm{CO}_{2}$ concentration in the ancient climate [3] coincide closely with peaks in past mass extinctions [83], mediated perhaps by acidification of ocean water [84,85]. Therefore, irrespective of the source of the contemporary global warming signal, and subject to further research, limiting anthropogenic $\mathrm{CO}_{2}$ emissions through existing and new international policy instruments such as the U.N. Framework Convention on Climate Change and the evolving Paris Climate Accords, respectively, may prove essential to preventing human-induced mass extinction of biodiversity.

Supplementary Materials: The following are available online at www.mdpi.com/2225-1154/6/1/3/s1.

Acknowledgments: This research was supported generally by the University of California, Santa Cruz, and the Environmental Studies Institute, a non-profit (501)(3)(c) corporation headquartered in Santa Cruz, CA, USA. This research did not receive any specific grants from funding agencies in the public, commercial or private sectors. Tax-deductible contributions to the research of the Environmental Studies Institute may be made through its website, www.EnvironmentalStudiesInstitute.org. We thank R.G. Plantz for helpful comments on earlier drafts.

Author Contributions: W. Jackson Davis conceived the research, performed most of the analysis, generated the figures and drafted the manuscript. Peter J. Taylor collaborated centrally on conceptual design and writing, editing, and literature research. W. Barton Davis produced the periodograms, performed related statistical analysis including development of confidence limits, performed the associated mathematical derivation of confidence limits described in the Supplementary Materials, provided general statistical counsel, and edited the draft manuscript. 
Conflicts of Interest: The authors declare no conflicts of interest.

\section{References}

1. Veizer, J.; Ala, D.; Azmy, K.; Bruckschen, P.; Buhl, D.; Bruhn, F.; Carden, G.A.F.; Diener, A.; Ebneth, S.; Godderis, Y.; et al. ${ }^{87} \mathrm{Sr} /{ }^{86} \mathrm{Sr}, \delta^{13} \mathrm{C}$ and $\delta^{18} \mathrm{O}$ evolution of Phanerozoic seawater. Chem. Geol. 1999, 161, 59-88. [CrossRef]

2. Prokoph, A.; Shields, G.A.; Veizer, J. Compilation and time-series analysis of a marine carbonate $\delta^{18} \mathrm{O}, \delta^{13} \mathrm{C}$, ${ }^{87} \mathrm{Sr} /{ }^{86} \mathrm{Sr}$ and $\delta^{34} \mathrm{~S}$ database through Earth history. Earth Sci. Rev. 2008, 87, 113-133. [CrossRef]

3. Davis, W.J. The relationship between atmospheric carbon dioxide concentration and global temperature for the last 425 million years. Climate 2017, 5, 76. [CrossRef]

4. Zachos, J.; Pagani, M.; Sloan, L.; Thomas, E.; Billups, K. Trends, rhythms, and aberrations in global climate $65 \mathrm{Ma}$ to present. Science 2001, 292, 686-693. [CrossRef] [PubMed]

5. Lisiecki, L.E.; Raymo, M.E. A Pliocene-Pleistocene stack of 57 globally distributed benthic $\delta^{18} \mathrm{O}$ records. Paleocean 2005, 20, 1003-1020. [CrossRef]

6. Huybers, P. Early Pleistocene glacial cycles and the integrated summer insolation forcing. Science 2006, 313, 508-511. [CrossRef] [PubMed]

7. Huybers, P. Combined obliquity and precession pacing of late Pleistocene deglaciations. Nature 2011, 480, 229-232. [CrossRef] [PubMed]

8. Raymo, M.E.; Oppo, D.W.; Curry, W. The mid-Pleistocene climate transition: A deep sea carbon isotopic perspective. Paleoceanography 1997, 12, 546-559. [CrossRef]

9. Tziperman, E.; Gildor, H. On the mid-Pleistocene transition to 100-kyr glacial cycles and the asymmetry between glaciation and deglaciation times. Paleoceanography 2003, 18. [CrossRef]

10. Medina-Elizalde, M.; Lea, D.W. The mid-Pleistocene transition in the tropical Pacific. Science 2005, 310, 1009-1012. [CrossRef] [PubMed]

11. Clark, P.U.; Archer, D.; Pollard, D.; Blum, J.D.; Rial, J.A.; Brovkin, V.; Mix, A.C.; Pisias, N.G.; Roy, M. The middle Pleistocene transition: Characteristics, mechanisms, and implications for long-term changes in atmospheric $\mathrm{pCO}_{2}$. Quat. Sci. Rev. 2006, 25, 3150-3184. [CrossRef]

12. Toggweiler, J.R. Shifting westerlies. Science 2009, 323, 1434-1435. [CrossRef] [PubMed]

13. Kemp, A.E.S.; Grigorov, I.; Pearce, R.B.; Naveira Garabato, A.C. Migration of the Antarctic Polar Front through the mid-Pleistocene transition: Evidence and climatic implications. Quat. Sci. Rev. 2010, 29, 1993-2009. [CrossRef]

14. Bates, S.L.; Siddall, M.; Waelbroeck, C. Hydrographic variations in ocean temperature over the mid-Pleistocene transition. Quat. Sci. Rev. 2014, 88, 147-158. [CrossRef]

15. Heinrich, H. Origin and consequences of cyclic ice rafting in the northeast Atlantic Ocean during the past 130,000 years. Quat. Res. 1988, 29, 142-152. [CrossRef]

16. Dansgaard, W.; Johnsen, S.J.; Clausen, H.B.; Dahl-Jensen, D.; Gundestrup, N.S.; Hammer, C.U.; Hvidberg, C.S.; Steffensen, J.P.; Svelnbjörnsdottir, A.E.; Jouzel, J.; et al. Evidence for general instability of past climate from a 250-kyr ice-core record. Nature 1993, 364, 218-220. [CrossRef]

17. Bond, G.C.; Broecker, W.; Johnsen, S.; McManus, J.; Labeyrie, L.; Jouzel, J.; Bonani, G. Correlations between climate records from North Atlantic sediments and Greenland ice. Nature 1993, 365, 143-147. [CrossRef]

18. Bond, G.C.; Lotti, R. Iceberg discharges into the North Atlantic on millennial time scales during the last glaciation. Science 1995, 267, 1005-1008. [CrossRef] [PubMed]

19. Bond, G.; Showers, W.; Cheseby, M.; Lotti, R.; Almasi, P.; deMenocal, P.; Priore, P.; Cullen, H.; Hajdas, I.; Bonani, G. A pervasive millennial-scale cycle in North Atlantic Holocene and glacial climates. Science 1997, 278, 1257-1266. [CrossRef]

20. Bond, G.C.; Showers, W.; Elliot, M.; Evans, M.N.; Lotti, R.; Hajdas, I.; Bonani, G.; Johnsen, S. The North Atlantic's 1-2 kyr climate rhythm: Relation to Heinrich events, Dansgaard/Oeschger cycles and the little ice age. In Mechanisms of Global Climate Change at Millennial Time Scales; Clark, P.U., Webb, R.S., Keigwin, L.D., Eds.; American Geophysical Union: Washington, DC, USA, 1999; pp. 35-68. ISBN 0-87590-095-X.

21. Bond, G.; Kromer, B.; Beer, J.; Muscheler, R.; Evans, M.N.; Showers, W.; Hoffman, S.; Lotti-Bond, R.; Hajdas, I.; Bonani, G. Persistent solar influence on North Atlantic climate during the Holocene. Science 2001, 294, 2130-2136. [CrossRef] [PubMed] 
22. Ditlevsen, P.D.; Andersen, K.K.; Svensson, A. The DO-climate events are probably noise induced: Statistical investigation of the claimed 1470 years cycle. Clim. Past 2007, 3, 129-134. [CrossRef]

23. Obrochta, S.P.; Miyahara, H.; Yokoyama, Y.; Crowley, T.J. A re-examination of evidence for the North Atlantic "1500-year cycle" at Site 609. Quat. Sci. Rev. 2012, 55, 23-33. [CrossRef]

24. Trenberth, K.E. Signal versus noise in the Southern Oscillation. Mon. Weather Rev. 1984, 112, $326-332$. [CrossRef]

25. Ropelewski, C.F.; Jones, P.D. An extension of the Tahiti-Darwin Southern Oscillation Index. Mon. Weather Rev. 1987, 115, 2161-2165. [CrossRef]

26. Villalba, R.; Lara, A.; Masiokas, M.H.; Urrutia, R.; Luckman, B.H.; Marshall, G.J.; Mundo, I.A.; Christie, D.A.; Cook, E.R.; Neukom, R.; et al. Unusual Southern Hemisphere tree growth patterns induced by changes in the Southern Annular Mode. Nat. Geosci. 2012, 5, 793-798. [CrossRef]

27. Abram, N.J.; Mulvaney, R.; Vimeux, F.; Phipps, S.J.; Turner, J.; England, M.H. Evolution of the Southern Annular Mode during the past millennium. Nat. Clim. Chang. 2014, 4, 564-569. [CrossRef]

28. Van den Broeke, M.R.; van Lipzig, N.P.M. Changes in Antarctic temperature, wind and precipitation in response to the Antarctic Oscillation. Ann. Glaciol. 2004, 39, 119-126. [CrossRef]

29. Screen, J.A.; Gillett, N.P.; Karpechko, A.Y.; Stevens, D.P. Mixed layer temperature response to the Southern Annular Mode: Mechanisms and model representation. J. Climatol. 2010, 23, 664-678. [CrossRef]

30. Yuan, X.; Yonekura, E. Decadal variability in the Southern Hemisphere. J. Geophys. Res. Atmos. 2011, 116, D19115. [CrossRef]

31. Ho, M.; Kiem, A.S.; Verdon-Kidd, D.C. The Southern Annular Mode: A comparison of indices. Hydrol. Earth Syst. Sci. 2012, 16, 967-982. [CrossRef]

32. Ekaykin, A.A.; Kozachek, A.V.; Lipenkov, V.-Y.; Shibaev, Y.A. Multiple climate shifts in the southern hemisphere over the past three centuries based on central Antarctic snow pits and core studies. Ann. Glaciol. 2014, 55, 259-266. [CrossRef]

33. Moberg, A.; Sonechkin, D.M.; Holmgren, K.; Datsenko, N.M.; Karlén, W. Highly variable Northern Hemisphere temperatures reconstructed from low- and high-resolution proxy data. Nature 2005, 433, 613-617. [CrossRef] [PubMed]

34. Liu, J.; Curry, J.A.; Wang, H.; Song, H.M.; Horton, R.M. Impact of declining Arctic sea ice on winter snowfall. Proc. Natl. Acad. Sci. USA 2012, 109, 4074-4079. [CrossRef] [PubMed]

35. Thompson, D.W.J.; Barnes, E. Periodic variability in the large-scale Southern Hemisphere atmospheric circulation. Science 2014, 343, 641-645. [CrossRef] [PubMed]

36. Petit, J.R.; Jouzel, J.; Raynaud, D.; Barkov, N.I.; Barnola, J.M.; Basile, I.; Bender, M.; Chappellaz, J.; Davis, J.; Delaygue, G.; et al. Climate and atmospheric history of the past 420,000 years from the Vostok ice core, Antarctica. Nature 1999, 399, 429-436. [CrossRef]

37. Petit, J.R.; Jouzel, J.; Raynaud, D.; Barkov, N.I.; Barnola, J.M.; Basile, I.; Bender, M.; Chappellaz, J.; Davis, J.; Delaygue, G.; et al. Vostok Ice Core Data for 420,000 Years; IGBP PAGES/World Data Center for Paleoclimatology Data Contribution Series \#2001-076; NOAA/NGDC Paleoclimatology Program: Boulder, OC, USA, 2001.

38. Veres, D.; Bazin, L.; Landais, A.; Kele, T.H.M.; Lemieux-Dudon, B.; Parrenin, F.; Martinerie, P.; Blayo, E.; Blunier, T.; Capron, E.; et al. The Antarctic ice core chronology (AICC2012): An optimized multi-parameter and multi-site dating approach for the last 120 thousand years. Clim. Past 2013, 9, 1733-1748. [CrossRef]

39. Bazin, L.; Landais, A.; Lemieux-Dudon, B.; Kele, H.T.M.; Veres, D.; Parrenin, F.; Martinerie, P.; Ritz, C.; Capron, E.; Lipenkov, V.; et al. An optimized multi-proxy, multi-site Antarctic ice and gas orbital chronology (AICC2012): 120-800 ka. Clim. Past 2013, 9, 1715-1731. [CrossRef]

40. Blunier, T.; Brook, E.J. Timing of millennial-scale climate change in Antarctica and Greenland during the last glacial period. Science 2001, 291, 109-112. [CrossRef] [PubMed]

41. USGCRP. 2017: Climate Science Special Report: A Sustained Assessment Activity of the U.S. Global Change Research Program; Wuebbles, D.J., Fahey, D.W., Hibbard, K.A., Dokken, D.J., Stewart, B.C., Maycock, T.K., Eds.; U.S. Global Change Research Program: Washington, DC, USA, 2017.

42. Wunsch, C. Quantitative estimate of the Milankovitch-forced contribution to observed Quaternary climate change. Quat. Sci. Rev. 2004, 23, 101-112. [CrossRef]

43. Jouzel, J. Calibrating the isotopic paleothermometer. Science 1999, 286, 910-911. [CrossRef] 
44. Nagornov, O.V.; Konovalov, Y.V.; Tchijov, V. Temperature reconstruction for Arctic glaciers. Paleogeogr. Palaeoclimatol. Paleoecol. 2006, 236, 125-134. [CrossRef]

45. Masson-Delmotte, V.; Hou, S.; Ekaykin, A.; Jouzel, J.; Aristariain, A.; Bernardo, R.T.; Bromwich, D.; Cattani, O.; Delmotte, M.; Falourd, S.; et al. A review of Antarctic surface snow isotopic composition: Observations, atmospheric circulation, and isotopic modeling. J. Clim. 2008, 21, 3359-3387. [CrossRef]

46. Grossman, E.L. Applying oxygen isotope paleothermometry in deep time. Paleontol. Soc. Pap. 2012, 18, 39-68. [CrossRef]

47. Lécuyer, C.; Amiot, R.; Touzeau, A.; Trotter, J. Calibration of the phosphate $\delta^{18} \mathrm{O}$ thermometer with carbonate-water oxygen isotope fractionation equations. Chem. Geol. 2013, 347, 217-226. [CrossRef]

48. Lee, J.-E.; Fung, I.; De Paolo, J.; Otto-Bliesner, B. Water isotopes during the Last Glacial Maximum: New general circulation model calculations. J. Geophys. Res. Atmos. 2008. [CrossRef]

49. EPICA Community Members. One-to-one coupling of glacial climate variability in Greenland and Antarctica. Nature 2006, 444, 195-198. [CrossRef]

50. Wilkinson, L.; Dallal, G.E. Tests of significance in forward selection regression with an F-to enter stopping rule. Technometrics 1981, 23, 377-380. [CrossRef]

51. Masson, V.; Vimeux, F.; Jouzel, J.; Morgan, V.; Delmotte, M.; Ciais, P.; Hammer, C.; Johnsen, C.; Lipenkov, V.Y.; Mosley-Thompson, E.; et al. Holocene climate variability in Antarctica based on 11 ice-core isotopic records. Quat. Res. 2000, 54, 348-358. [CrossRef]

52. Blunier, T.; Chappellaz, J.; Schwander, J.; Dällenbach, A.; Stauffer, B.; Stocker, T.F.; Raynaud, D.; Jouzel, J.; Clausen, H.B.; Hammer, C.U.; et al. Asynchrony of Antarctic and Greenland climate change during the last glacial period. Nature 1998, 394, 739-743. [CrossRef]

53. Pedro, J.B.; van Ommen, T.D.; Rasmussen, S.O.; Morgan, V.I.; Chappellaz, J.; Moy, A.D.; Masson-Delmotte, V.; Delmotte, M. The last deglaciation: Timing the bipolar seesaw. Clim. Past 2011, 7, 671-683. [CrossRef]

54. Pedro, J.B.; van Ommen, T.D.; Rasmussen, S.O.; Morgan, V.I.; Chappellaz, J.; Moy, A.D.; Masson-Delmotte, V.; Delmotte, M. Antarctic Ice Core Deglacial Water Isotope Data on GICC05 Time Scale; IGBP PAGES/World Data Center for Paleoclimatology Data Contribution Series \#2011-088; NOAA/NCDC Paleoclimatology Program: Boulder, CO, USA, 2011.

55. Yokoyama, Y.; Lambeck, K.; De Deckker, P.; Johnston, P.; Fifield, L.K. Timing of the Last Glacial Maximum from observed sea-level minima. Nature 2000, 406, 713-716. [CrossRef] [PubMed]

56. Liu, Y.; Cai, Q.F.; Song, H.M.; An, Z.S.; Hans, W.L. Amplitudes, rates, periodicities and causes of temperature variations in the past 2485 years and future trends over the central-eastern Tibetan Plateau. Chin. Sci. Bull. 2011, 56, 2986-2994. [CrossRef]

57. Moffa-Sánchez, P.; Born, A.; Hall, I.R.; Thornalley, D.J.R.; Barker, S. Solar forcing of North Atlantic surface temperature and salinity over the past millennium. Nat. Geosci. 2014, 7, 275-278. [CrossRef]

58. Ruddiman, W.F. The anthropogenic greenhouse era began thousands of years ago. Clim. Chang. 2003, 61, 261-293. [CrossRef]

59. Miehe, G.; Miehe, S.; Böhner, J.; Kaiser, K.; Hensen, I.; Madsen, D.; Liu, J.Q.; Opgenoorth, L. How old is the human footprint in the world's largest alpine ecosystem? A review of multiproxy records from the Tibetan Plateau from the ecologist's viewpoint. Quat. Sci. Rev. 2014, 86, 190-209. [CrossRef]

60. Jouzel, J. Ice cores north and south. Nature 1994, 372, 612-613. [CrossRef]

61. Bender, M.; Sowers, T.; Dickson, M.-L.; Orchardo, J.; Grootes, P.; Mayewski, P.A.; Meese, D.A. Climate correlations between Greenland and Antarctica during the past 100,000 years. Nature 1994, 372, 663-666. [CrossRef]

62. Steig, E.J.; Brook, E.J.; White, J.W.C.; Sucher, C.M.; Bender, M.L.; Lehman, S.J.; Morse, D.L.; Waddington, E.D.; Clow, G.D. Synchronous climate changes in Antarctica and the North Atlantic. Science 1998, 282, 92-95. [CrossRef] [PubMed]

63. Morgan, V.; Delmotte, M.; van Ommen, T.; Jouzel, J.; Chappellaz, J.; Woon, S.; Masson-Delmotte, V.; Raynaud, D. Relative timing of deglacial climate events in Antarctica and Greenland. Science 2002, 297, 1862-1864. [CrossRef] [PubMed]

64. Andres, M.S.; Bernasconi, S.I.; McKenzie, J.A.; Röhl, U. Southern Ocean deglacial record supports global Younger Dryas. Earth Planet. Sci. Lett. 2003, 216, 515-524. [CrossRef] 
65. Brook, E.J.; White, J.W.C.; Schilla, A.S.M.; Bender, M.L.; Barnett, B.; Severinghaus, J.P.; Taylor, K.C.; Alley, R.B.; Steig, E.J. Timing of millennial-scale climate change at Siple Dome, West Antarctica, during the last glacial period. Quat. Sci. Rev. 2005, 24, 1333-1343. [CrossRef]

66. Jouzel, J.; Masson-Delmotte, V.; Cattani, O.; Dreyfus, G.; Falourd, S.; Hoffmann, G.; Minster, B.; Nouet, J.; Barnola, J.M.; Chappellaz, J.; et al. Orbital and millennial Antarctic climate variability over the past 800,000 years. Science 2007, 317, 793-797. [CrossRef] [PubMed]

67. Stenni, B.; Buiron, D.; Frezzotti, M.; Albani, S.; Barbante, C.; Bard, E.; Barnola, J.M.; Baroni, M.; Baumgartner, M.; Bonazza, M.; et al. Expression of the bipolar see-saw in Antarctic climate records during the last deglaciation. Nat. Geosci. 2011, 4, 46-49. [CrossRef]

68. Rial, J.A. Synchronization of polar climate variability over the last ice age: In search of simple rules at the heart of climate's complexity. Am. J. Sci. 2012, 312, 417-448. [CrossRef]

69. Tachikawa, K.; Timmermann, A.; Vidal, L.; Sonzogni, C.; Timm, O.E. $\mathrm{CO}_{2}$ radiative forcing and Intertropical Convergence Zone influences on western Pacific warm pool climate over the past $400 \mathrm{ka}$. Quat. Sci. Rev. 2014, 86, 24-34. [CrossRef]

70. Landais, A.; Masson-Delmotte, V.; Stenni, B.; Selmo, E.; Roche, D.M.; Jouzel, J.; Lambert, F.; Guillevic, M.; Bazin, L.; Arzel, O.; et al. A review of the bipolar see-saw from synchronized and high-resolution ice core water stable isotope records from Greenland and East Antarctica. Quat. Sci. Rev. 2015, 114, 18-32. [CrossRef]

71. WAIS Divide Project Members. Precise interpolar phasing of abrupt climate change during the last ice age. Nature 2015, 520, 661-665. [CrossRef]

72. Turney, C.S.M.; Jones, R.T.; Fogwill, C.J.; Hatton, J.; Williams, A.N.; Hogg, A.G.; Thomas, Z.A.; Palmer, J.; Mooney, S.; Reimer, R.W. A 250-year periodicity in Southern Hemisphere westerly winds over the last 2600 years. Clim. Past 2016, 12, 189-200. [CrossRef]

73. Dennell, R.W.; Martinón-Torres, M.; Bermúdez de Castro, J.M. Hominin variability, climate instability and population demography in middle Pleistocene Europe. Quat. Sci. Rev. 2011, 30, 1511-1524. [CrossRef]

74. Billups, K.; Scheinwald, A. Origin of millennial-scale climate signals in the subtropical North Atlantic. Paleoceanography 2014, 29, 612-627. [CrossRef]

75. Andersen, C.; Koç, N.; Moros, M. A highly unstable Holocene climate in the subpolar North Atlantic: Evidence from diatoms. Quat. Sci. Rev. 2004, 23, 2155-2166. [CrossRef]

76. Khider, D.; Jackson, C.S.; Stott, L.D. Assessing millennial-scale variability during the Holocene: A perspective from the western tropical Pacific. Paleoceanography 2014, 29, 143-159. [CrossRef]

77. Alley, R.B.; Marotzke, J.; Nordhaus, W.; Overpeck, J.; Peteet, D.; Pielke, R., Jr.; Pierrehumbert, R.; Rhines, P.; Stocker, T.; Talley, L.; et al. Abrupt Climate Change: Inevitable Surprises; National Research Council: Washington, DC, USA, 2002; 230p, ISBN 0-309-07434-7.

78. Jones, J.M. Climate science: Tree rings and storm tracks. Nat. Geosci. 2012, 5, 764-765. [CrossRef]

79. Jones, J.M.; Gille, S.T.; Goosse, H.; Abram, N.J.; Canziana, P.O.; Charman, D.J.; Clem, K.R.; Crosta, X.; Lavergne, C.D.; Eisenman, I.; et al. Assessing recent trends in high-latitude Southern Hemisphere surface climate. Nat. Clim. Chang. 2016, 6, 917-926. [CrossRef]

80. Fyfe, J.C.; Gillett, N.P.; Zwiers, F.W. Overestimated global warming over the past 20 years. Nat. Clim. Chang. 2013, 3, 767-769. [CrossRef]

81. Tollefson, J. The case of the missing heat. Nature 2014, 505, 276-278. [CrossRef] [PubMed]

82. Trenberth, K.E.; Fasullo, J.T. An apparent hiatus in global warming? Earth's Future 2013, 1, 19-32. [CrossRef]

83. Bambach, R.K. Phanerozoic biodiversity mass extinctions. Ann. Rev. Earth Planet. Sci. 2006, 34, 127-155. [CrossRef]

84. Doney, S.C.; Fabry, V.J.; Feely, R.A.; Kleypas, J.A. Ocean acidification: The other $\mathrm{CO}_{2}$ problem. Ann. Rev. Mar. Sci. 2009, 1, 169-192. [CrossRef] [PubMed]

85. Weinbauer, M.G.; Mari, X.; Gattuso, J.-P. Effects of ocean acidification on the diversity and activity of heterotrophic marine microorganisms. In Ocean Acidification; Gattuso, J.-P., Hansson, L., Eds.; Oxford University Press: New York, NY, USA, 2012; pp. 83-98. ISBN 978-0-19-959108-4.

(C) 2018 by the authors. Licensee MDPI, Basel, Switzerland. This article is an open access article distributed under the terms and conditions of the Creative Commons Attribution (CC BY) license (http://creativecommons.org/licenses/by/4.0/). 